\title{
Dynamic Fracture Evolution and Mechanical Behavior of Sandstone Containing Noncoplanar Elliptical Flaws under Impact Loading
}

\author{
Zhenyu Han, Diyuan Li (D), Quanqi Zhu, Meng Liu, and Zhi Sun \\ School of Resources and Safety Engineering, Central South University, Changsha, Hunan 410083, China \\ Correspondence should be addressed to Diyuan Li; diyuan.li@csu.edu.cn
}

Received 5 May 2018; Accepted 12 September 2018; Published 1 November 2018

Guest Editor: Qianbing Zhang

Copyright (c) 2018 Zhenyu Han et al. This is an open access article distributed under the Creative Commons Attribution License, which permits unrestricted use, distribution, and reproduction in any medium, provided the original work is properly cited.

\begin{abstract}
To investigate the effects of preexisting flaws with different geometries, including flaw inclination angle and ligament angle on dynamic strength, deformation properties, and fracture evolution of rock materials, a series of dynamic impact tests were conducted on green sandstone specimens containing double elliptical flaws using a $75 \mathrm{~mm}$ diameter split Hopkinson pressure bar (SHPB) testing device with a high-speed camera recording in real time. The experimental results show that dynamic strength of specimens with different flaw angles is reduced between $5.91 \%$ and $39.92 \%$ but from $18.50 \%$ to $28.44 \%$ for specimens with different ligament angles, indicating that the effect of the flaw angle on the dynamic strength is more significant than that of the ligament angle. However, the dynamic deformation properties are influenced greatly by the ligament angle. Macroscale cracks mostly initiate at or near the flaw tips and then propagate in different paths with varying flaw geometries, leading to the ultimate failure in five typical modes based on the crack coalescence. Shear crack coalescence and tensile crack coalescence are identified through both macroscopic fracturing photos taken by the high-speed camera and microscopic surface morphology obtained by the scanning electron microscope (SEM).
\end{abstract}

\section{Introduction}

Rock mass is a complex natural medium containing various defects, such as flaws, fissures, pores, and holes, where new cracks always initiate, then propagate, and coalesce with each other into macroscale fractures, leading to the rapid damage and failure to lower the stability of rock structures such as underground mining craven and tunneling [1-4]. Therefore, the investigation of mechanical properties and fracturing process of brittle rock materials with preexisting defects is helpful to guide the underground excavation scientifically.

There have been a large number of experimental and simulative works carried out to study the crack initiation, propagation, and coalescence of rock and rock-like materials with preexisting flaws under static loading. For a single crack-like flaw, wing cracks first generate at the flaw tips and then grow along the axial stress direction, and subsequently, secondary cracks emerge around the flaw tip and propagate in the coplanar or oblique direction with the preexisting flaw [5-10]. For a single hole-like flaw, crack propagation is a progressive development of high major principal strain zones based on DIC (digital image correlation) [11-13], dominantly resulting in an axial splitting failure mode [14]. Great efforts also have been devoted to study the effect of multiple crack-like flaws on the mechanical and fracture behaviors. Bobet and Einstein [15], Wong and Chau [16], Sagong and Bobet [17], Yang et al. [18, 19], Park and Bobet [20], and Gratchev et al. [21] investigated the influence of flaw geometries, including flaw number, length, width, frictional coefficient, inclination angle, and ligament angle, on mechanical properties, crack initiation, fracturing process, coalescence, and ultimate failure. Some scholars conducted experiments in more complicated conditions, for instance, an environment-coupled stress, fluid flow, and changing chemical [22], conventional triaxial compressive 


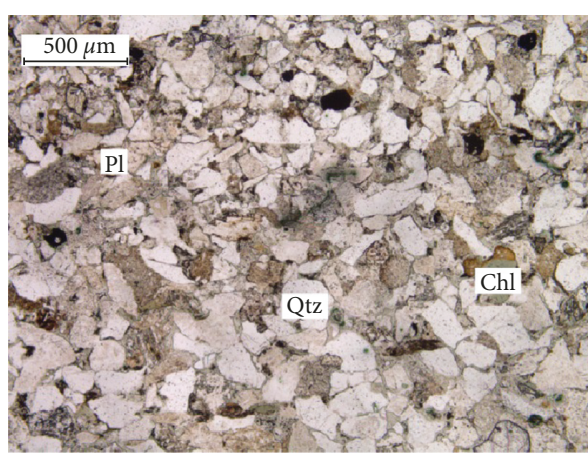

(a)

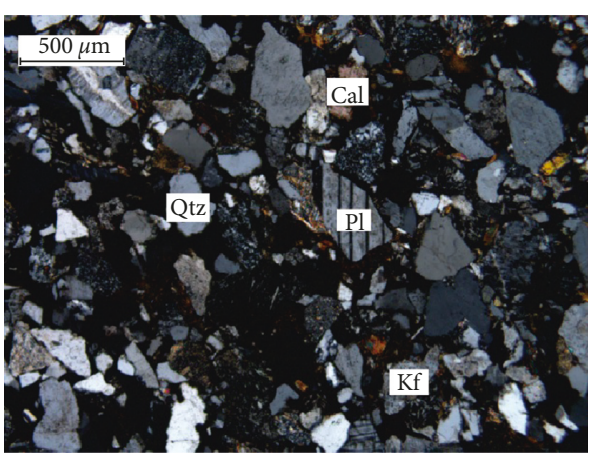

(b)

Figure 1: Microscopic structure by mineral composition and optical microscopy analysis: (a) plane-polarized light; (b) perpendicular polarized light.

TABLE 1: Basic physical and mechanical properties of the sandstone.

\begin{tabular}{lc}
\hline Properties & Values \\
\hline Young's modulus, $E(\mathrm{GPa})$ & 10.67 \\
Poisson's ratio, $v$ & 0.14 \\
Uniaxial static compressive strength, $\sigma_{\mathrm{c}}(\mathrm{MPa})$ & 69.17 \\
Static Brazilian tensile strength, $\sigma_{\mathrm{st}}(\mathrm{MPa})$ & 5.29 \\
Dynamic Brazilian tensile strength, $\sigma_{\mathrm{dt}}(\mathrm{MPa})$ & 9.79 \\
Density, $\gamma\left(\mathrm{kg} / \mathrm{m}^{3}\right)$ & 2377.71 \\
Porosity $(\%)$ & 6.28 \\
Longitudinal wave velocity, $V_{\mathrm{p}}(\mathrm{m} / \mathrm{s})$ & 2973.11 \\
\hline
\end{tabular}

tests [23], combined static and dynamic loading [24], hightemperature treatment [25], cyclic uniaxial compressions [26], and 3D printing materials [27]. Extensive researches also have been done on fracturing processes on rock with multiple hole-like flaws. Lajtai and Lajtai [28] introduced failure modes based on interactions involved in the collapse of cavities. Lin et al. [29] performed uniaxial compressive tests to find whether the coalescence mechanisms for samples with multiple holes depend on the bridge angle and the normalized bridge length and proposed a modified Sammis and Ashby [30] crack model to predict the peak stress. Uniaxial compressive tests, AE measuring method, photographic monitoring technique, and PFC numerical simulation were conducted by Huang et al. [31] to study cracking process and failure modes by using granite specimens containing three preexisting holes, showing that they were all in very good agreement with each other. Yang et al. [32] summarized four distinct modes based on uniaxial compressive tests of sandstone specimens with two oval flaws: no crack coalescence failure, indirect crack coalescence outside the bridge area failure, single crack coalescence inside the bridge area failure, and tensile crack coalescence outside the bridge area failure.

Under dynamic loading conditions, there has been less number of studies on the dynamic mechanical properties and fracturing evolution of defected rocks. Shear cracks initiate earlier and dominate the propagation process of single crack-like flawed specimens under a high loading rate by numerical simulation [33] and experimental tests [10]. Li et al. [34] and Li et al. [35] systematically investigated the effects of a single crack-like or hole-like flaw on the dynamic mechanical properties and fracturing behavior. They found that peak stress and corresponding strain were obviously influenced by flaw shapes. Six typical crack types are identified, and the final failure modes are all in X shape. Jiang et al. [36] used gypsum-like 3D printing materials to analyze the dynamic crack coalescence, and the results of which were consistent with that of the traditional materials like cement concrete and natural rock. Marble specimens with double flaws at the end surfaces were also studied by Li et al. [37], showing that there would be a critical inclination angle to maximize the dynamic strength, Young's modulus, and energy absorption. Crack propagation characteristics and failure patterns on both sides of the critical angle are rather symmetric.

In the present study, dynamic impact tests are performed using prismatic green sandstone specimens to investigate the effect of flaw inclination angle and ligament angle on dynamic mechanic properties and fracture mechanisms with a high-speed camera recording in real time.

\section{Experimental Preparation and Loading Procedure}

2.1. Sandstone Material. Sandstone is widely used to investigate the cracking behavior of defected rock because of its crystalline and blocky structure [24, 38, 39]. A type of green sandstone, taken from Neijiang city, Sichuan province, China, was used for the present dynamic compressive tests. As shown in Figure 1, the minerals in the sandstone specimens are mainly quartz (28\%), plagioclase (24\%), orthoclase (19\%), chlorite (18\%), and siliceous rock debris (7\%), with grain sizes varying from 0.04 to $0.35,0.07$ to 0.35 , 0.1 to $0.4,0.1$ to 0.3 , and 0.005 to $0.01 \mathrm{~mm}$, respectively. A detailed physical and mechanical description of the sandstone is given in Table 1.

2.2. Specimen Preparation. In this experiment, all specimens were cut along the same direction from the same sandstone block to ensure the isotropy and uniformity of the test results. According to the method suggested by the ISRM [40] 
and the validity of using prismatic rock specimens in the split Hopkinson pressure bar (SHPB) tests [41], the tested specimens were made with the length to width ratio of 1.0 to minimize the influence of end friction effects on the test results. Therefore, the sandstones were processed into rectangular samples, $60 \mathrm{~mm}$ in length $(L), 60 \mathrm{~mm}$ in width $(W)$, and $25 \mathrm{~mm}$ in thickness $(T)$. All surfaces of the sample were grinded and polished to make unevenness and nonperpendicularity less than $0.02 \mathrm{~mm}$.

The geometry of double elliptical flaws is defined by five geometrical parameters: flaw inclination angle $\alpha$ (the angle between major axis of elliptical flaw and loading direction), ligament angle $\beta$ (the angle between the bridge and loading direction), the length of major axis $2 a=15 \mathrm{~mm}$, the length of the minor axis $2 b=5 \mathrm{~mm}$, and the length of the rock bridge $2 c=10 \mathrm{~mm}$, as shown in Figure 2. The specimens were prepared in three groups, where group I (intact specimens) is referred for comparison, and groups II and III contain specimens with a constant ligament angle $\beta$ but different inclination angles $\alpha$ and specimens with a constant inclination angle $\alpha$ but different ligament angles $\beta$, respectively. The length of the major axis, minor axis, and rock bridge are constant for all specimens. The preexisting flaws were produced by the high-pressure water jet cutting method, which has been proven to cause no disturbance and damage to the other parts of the specimen [34]. Detailed description of sandstone specimens with different flaw geometries is listed in Table 2. The specimen number describes the type of rock, flaw inclination angle, and ligament angle. For example, S-45-60 denotes a double-flawed sandstone specimen with $\alpha=45^{\circ}$ and $\beta=60^{\circ}$.

2.3. Testing Apparatus. The modified large diameter split Hopkinson pressure bar (SHPB) test system $[42,43]$ in the Central South University is adopted. It comprises a gas gun, a cone-shaped striker, an incident bar $(2000 \mathrm{~mm})$, a transmitted bar $(2000 \mathrm{~mm})$, an absorbed bar $(800 \mathrm{~mm})$, and a data acquisition system (a CS-1D superdynamic strainometer coupled with a DL750 digital oscilloscope). The striker and bars are made from high-strength $40 \mathrm{Cr}$ alloy steel, the diameter, P-wave velocity, elastic modulus, and density of which are $75 \mathrm{~mm}, 5400 \mathrm{~m} / \mathrm{s}, 240 \mathrm{GPa}$, and $7800 \mathrm{~kg} / \mathrm{m}^{3}$, respectively.

During tests, the specimen is clamped between the incident and transmitted bars. A slowly rising half sine wave is generated when the cone-shaped striker impacts on the front surface of the incident bar, which can effectively avoid the stress uneven before the failure of the specimens. Strain pulses (Figure 3 ) are collected in real time by the CS-1D superdynamic strainometer coupled with strain gauges mounted in the bars, displayed and stored by a digital oscilloscope combined with a computer. The assumption of one-dimensional stress wave theory can be achieved by using large slenderness ratio bars. The assumption of stress equilibrium before failure can be achieved well by using a cone-shaped striker (Figure 4). Based on the "3-wave analysis" [44, 45], the axial stress $\sigma(t)$, strain $\varepsilon(t)$, and strain rate $\dot{\varepsilon}(t)$ can be derived by the following equations:

$$
\begin{aligned}
& \sigma(t)=\frac{A_{\mathrm{e}} E_{\mathrm{e}}}{2 A_{\mathrm{s}}}\left[\varepsilon_{\mathrm{I}}(t)+\varepsilon_{\mathrm{R}}(t)+\varepsilon_{\mathrm{T}}(t)\right], \\
& \varepsilon(t)=\frac{C_{\mathrm{e}}}{L_{\mathrm{s}}} \int_{0}^{t}\left[\varepsilon_{\mathrm{I}}(t)-\varepsilon_{\mathrm{R}}(t)-\varepsilon_{\mathrm{T}}(t)\right] d t, \\
& \dot{\varepsilon}(t)=\frac{C_{\mathrm{e}}}{L_{\mathrm{s}}} \int_{0}^{t}\left[\varepsilon_{\mathrm{I}}(t)-\varepsilon_{\mathrm{R}}(t)-\varepsilon_{\mathrm{T}}(t)\right],
\end{aligned}
$$

where $A_{\mathrm{e}}, C_{\mathrm{e}}$, and $E_{\mathrm{e}}$ are the cross-sectional area, P-wave velocity, and Young's modulus of the elastic bar, respectively. $A_{\mathrm{s}}$ and $L_{\mathrm{s}}$ are the cross-sectional area and length of the specimen, respectively. $\varepsilon_{\mathrm{I}}(t), \varepsilon_{\mathrm{R}}(t)$, and $\varepsilon_{\mathrm{T}}(t)$ are incident, reflected, and transmitted strain pulses, respectively.

In order to observe the fracture behaviors of defected specimens, a high-speed camera is always used for synchronously recording the failure process [7]. During the testing process, a FASTCAM SA1.1 high-speed camera under the illumination of a high-intensity flash light was placed perpendicularly to the specimens so as to capture the images, simultaneously storing in a computer for subsequent processing. The frame rate of the camera is $75000 \mathrm{fps}$ (frames per second) with a resolution of $256 \times 208$ pixels so that it can capture a picture each $13.3 \mu \mathrm{s}$.

\section{Dynamic Strength and Deformation Properties}

3.1. Mechanical Properties of Flawed Sandstone with Different Flaw Inclination Angles. In the present dynamic tests, the peak strain $\varepsilon_{\mathrm{d}}$ is defined as the strain corresponding to the peak stress $\sigma_{\mathrm{d}}$ and dynamic Young's modulus $E_{50}$ is defined as the ratio of the half of the peak stress to the corresponding strain. Table 2 lists the values of dynamic compressive strength $\sigma_{\mathrm{d}}$, Young's modulus $E_{50}$, peak strain $\varepsilon_{\mathrm{d}}$, and strain rate $\dot{\varepsilon}$ of intact and defected sandstone specimens. It is obvious that the dynamic strength and corresponding strain of the defected specimens are all lower than those of the intact specimen.

Figures 5-8 reveal the influence of the flaw angle on the strength and deformation parameters of sandstone specimens. The dynamic stress-strain curves of sandstone specimens containing two elliptical flaws with different flaw angles are shown in Figure 5. It is very clear that the flaw angle has a distinct effect on the curve shape especially for $\alpha>0^{\circ}$. It can be seen from Figure 6 that dynamic strength of the defected sandstone specimens with a constant ligament angle decreases with the flaw angle increasing, reaching the minimum value of $76.30 \mathrm{MPa}$ when $\alpha=90^{\circ}$. When the flaw angle increases from $0^{\circ}$ to $15^{\circ}$ and from $75^{\circ}$ to $90^{\circ}$, the dynamic strength marginally decreases with a reduction from $5.91 \%$ to $6.29 \%$ and from $39.76 \%$ to $39.92 \%$ (compared to the intact specimen). When the flaw angle increases from $15^{\circ}$ to $75^{\circ}$, the dynamic strength dramatically decreases with a reduction from $6.29 \%$ to $39.76 \%$. Notably, the magnitude of the strength reduction in the range of $15^{\circ} \sim 75^{\circ}$ is much higher than that in the range of $0^{\circ} \sim 15^{\circ}$ and $75^{\circ} \sim 90^{\circ}$. 

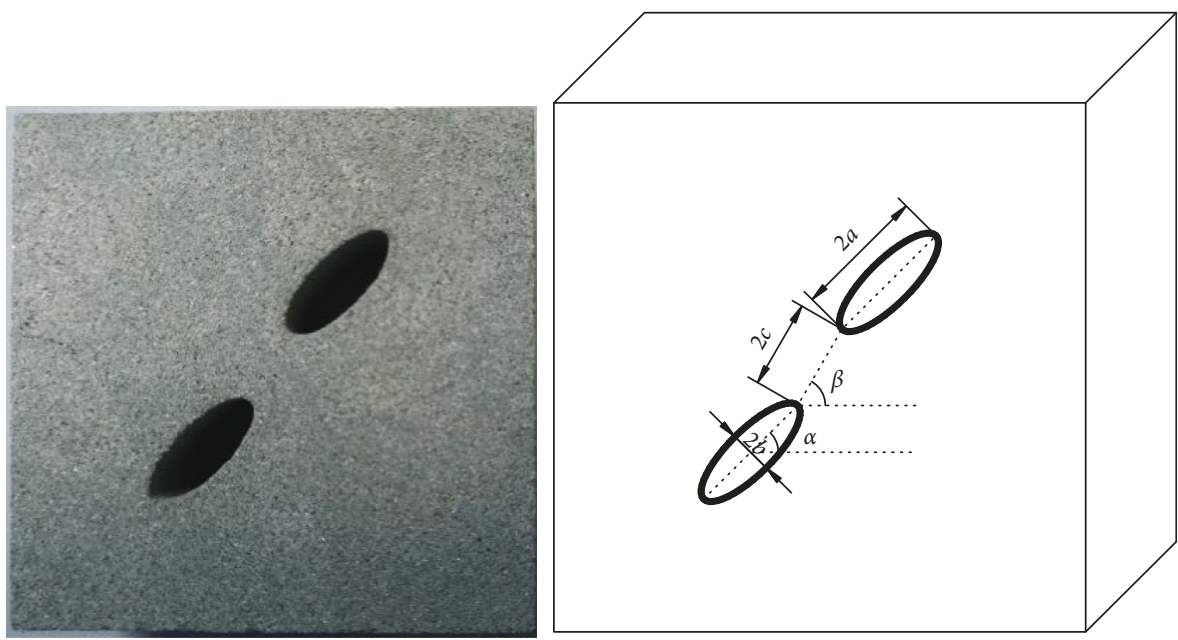

Figure 2: Geometry of the double-flawed sandstone specimen named S-45-60.

TABLe 2: Geometrical sizes and mechanical parameters of sandstone specimens.

\begin{tabular}{|c|c|c|c|c|c|c|c|c|c|c|}
\hline \multirow[b]{2}{*}{$\begin{array}{l}\text { Specimen } \\
\text { no. }\end{array}$} & \multirow[b]{2}{*}{$\begin{array}{c}L \\
(\mathrm{~mm})\end{array}$} & \multirow[b]{2}{*}{$\begin{array}{c}W \\
(\mathrm{~mm})\end{array}$} & \multirow[b]{2}{*}{$\begin{array}{c}H \\
(\mathrm{~mm})\end{array}$} & \multicolumn{2}{|c|}{ Flaw } & \multirow[b]{2}{*}{$\sigma_{\mathrm{d}}(\mathrm{MPa})$} & \multirow[b]{2}{*}{$\begin{array}{c}E_{50} \\
(\mathrm{GPa})\end{array}$} & \multirow[b]{2}{*}{$\varepsilon_{\mathrm{d}}\left(10^{-2}\right)$} & \multirow[b]{2}{*}{$\begin{array}{c}\dot{\varepsilon} \\
\left(\mathrm{s}^{-1}\right)\end{array}$} & \multirow[b]{2}{*}{ Note } \\
\hline & & & & $\begin{array}{c}\alpha \\
\left({ }^{\circ}\right)\end{array}$ & $\begin{array}{l}\beta \\
\left({ }^{\circ}\right)\end{array}$ & & & & & \\
\hline$\overline{S_{0}}$ & 60.58 & 60.70 & 25.81 & - & - & 127 & 13.1 & 0.965 & 77.1 & \multirow{8}{*}{$\begin{array}{l}\text { Flaw inclination angle (ranging from } 0^{\circ} \text { to } \\
90^{\circ} \text { ) }\end{array}$} \\
\hline S-0-0 & 60.21 & 61.36 & 25.65 & 0 & 0 & 119.5 & 16.3 & 0.687 & 69.0 & \\
\hline S-15-0 & 60.87 & 61.87 & 26.58 & 15 & 0 & 119 & 14.5 & 0.818 & 68.2 & \\
\hline S-30-0 & 60.53 & 60.80 & 25.56 & 30 & 0 & 112 & 13.4 & 0.834 & 70.9 & \\
\hline S-45-0 & 61.05 & 60.34 & 25.18 & 45 & 0 & 98.5 & 11.6 & 0.849 & 72.8 & \\
\hline$S-60-0$ & 60.80 & 60.75 & 24.59 & 60 & 0 & 90.7 & 10.5 & 0.864 & 74.8 & \\
\hline S-75-0 & 60.60 & 60.75 & 25.38 & 75 & 0 & 76.5 & 8.9 & 0.855 & 72.5 & \\
\hline S-90-0 & 61.82 & 60.49 & 26.27 & 90 & 0 & 76.3 & 10.2 & 0.748 & 72 & \\
\hline S-45-30 & 60.03 & 60.26 & 26.36 & 45 & 30 & 91.5 & 11.0 & 0.567 & 70.0 & \multirow{5}{*}{ Ligament angle (ranging from $30^{\circ}$ to $150^{\circ}$ ) } \\
\hline S-45-60 & 60.43 & 60.08 & 25.72 & 45 & 60 & 90.8 & 11.1 & 0.713 & 73.5 & \\
\hline S-45-90 & 59.90 & 61.02 & 25.38 & 45 & 90 & 103.5 & 12.6 & 0.467 & 69.3 & \\
\hline S-45-120 & 60.91 & 60.39 & 25.63 & 45 & 120 & 102 & 11.4 & 0.891 & 70.0 & \\
\hline S- $45-150$ & 60.95 & 61.05 & 26.02 & 45 & 150 & 100 & 10.4 & 0.960 & 77.7 & \\
\hline
\end{tabular}

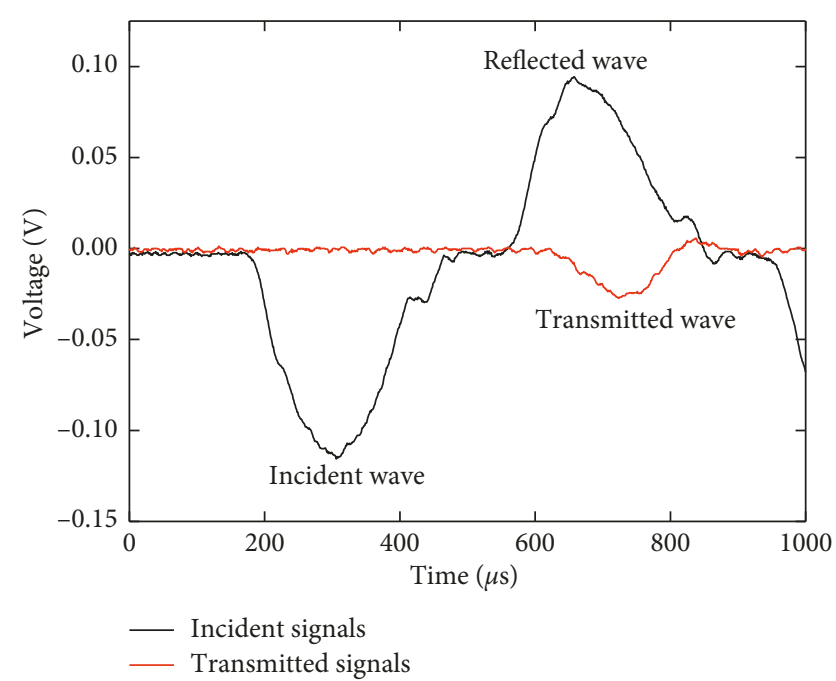

Figure 3: Typical impulse waveforms of the sandstone specimen S-60-0.

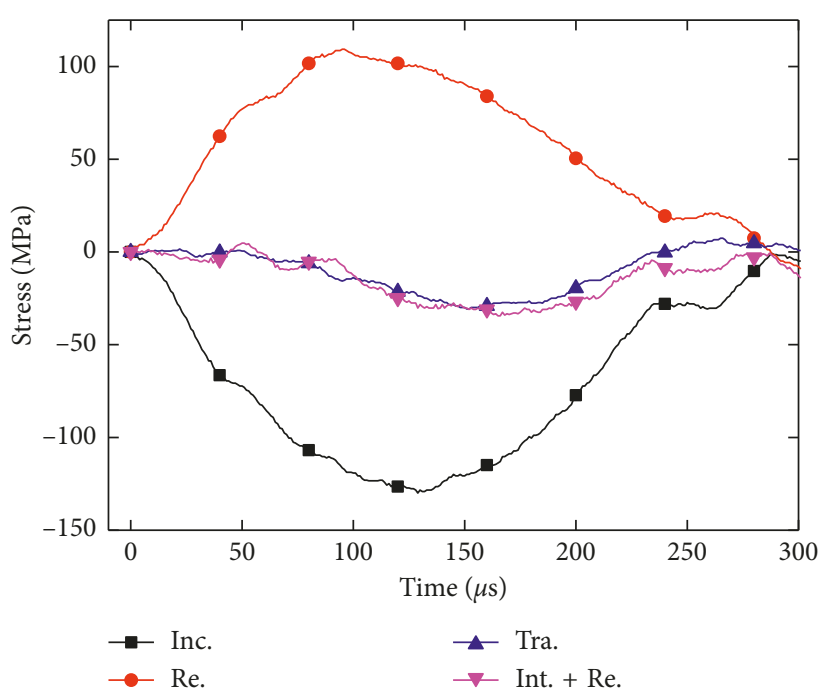

FIgURE 4: Stress equilibrium of the sandstone specimen S-60-0 between incident and transmitted bars. 


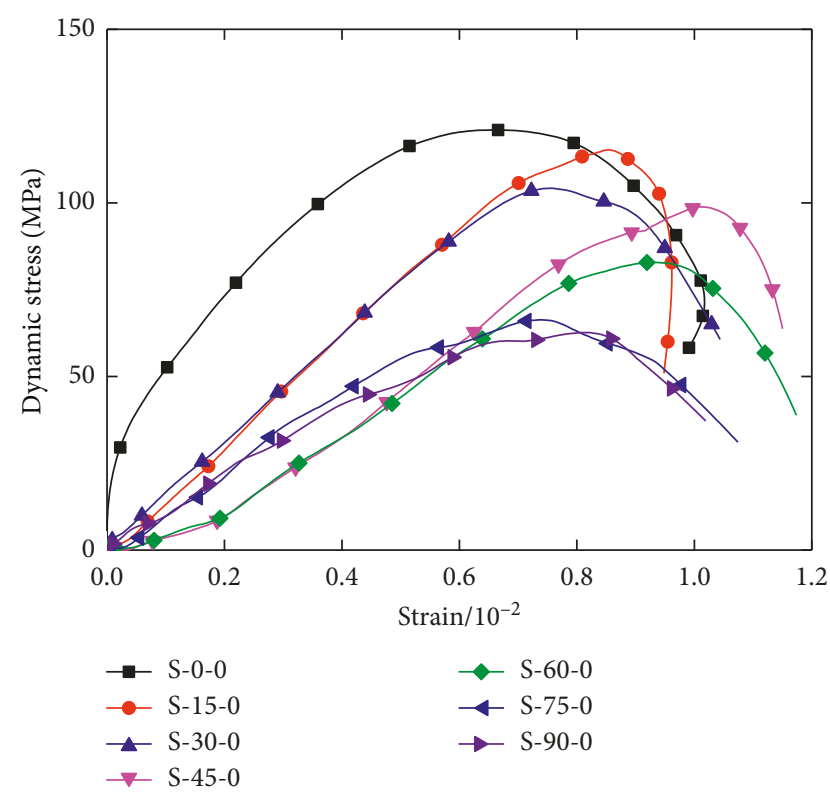

FIGURE 5: Influence of the flaw angle on the dynamic stress-strain curves of specimens with a constant ligament angle of $0^{\circ}$.

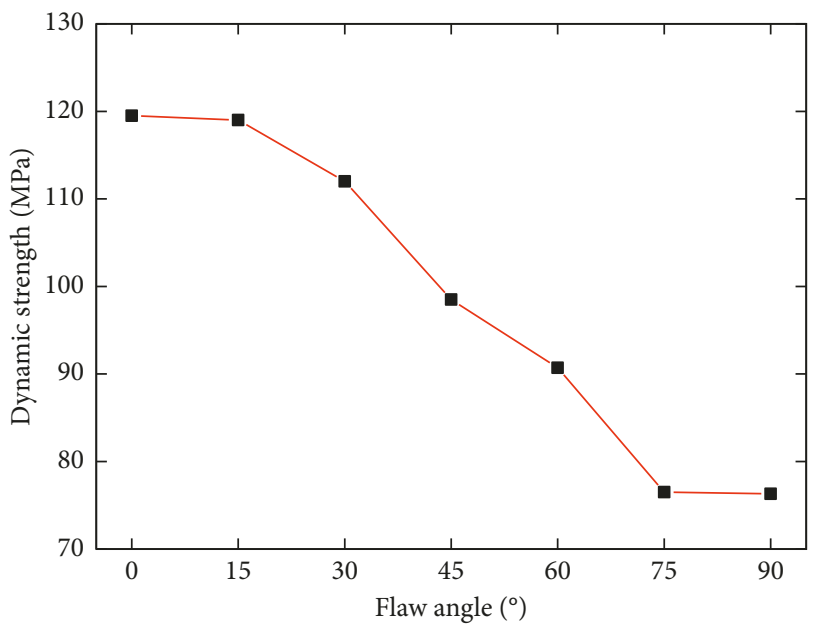

FIGURE 6: Influence of the flaw angle on the dynamic strength of specimens with a constant ligament angle of $0^{\circ}$.

Figure 7 depicts the influence of the flaw angle on the dynamic Young's modulus of defected sandstone specimens. It first decreases to its lowest value of $8.95 \mathrm{GPa}$ at $\alpha=75^{\circ}$ then increases as $\alpha$ increases to $90^{\circ}$. The influence of the flaw angle on the dynamic Young's modulus is similar to that on the dynamic strength.

The relationship between the peak strain and flaw angle is plotted in Figure 8. The dynamic peak strain increases when $\alpha$ ranges from $0^{\circ}$ to $60^{\circ}$, reaching the maximum value of $0.864 \%$ when $\alpha=60^{\circ}$ but then decreases between $60^{\circ}$ and $90^{\circ}$.

3.2. Mechanical Properties of Flawed Sandstone with Different Ligament Angles. The dynamic mechanical and

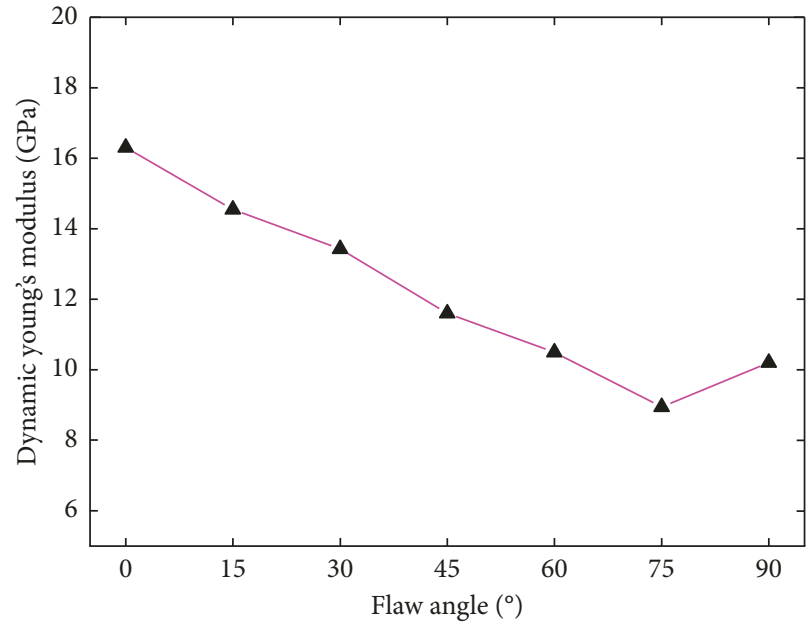

FIgURE 7: Influence of the flaw angle on the dynamic Young's modulus of specimens with a constant ligament angle of $0^{\circ}$.

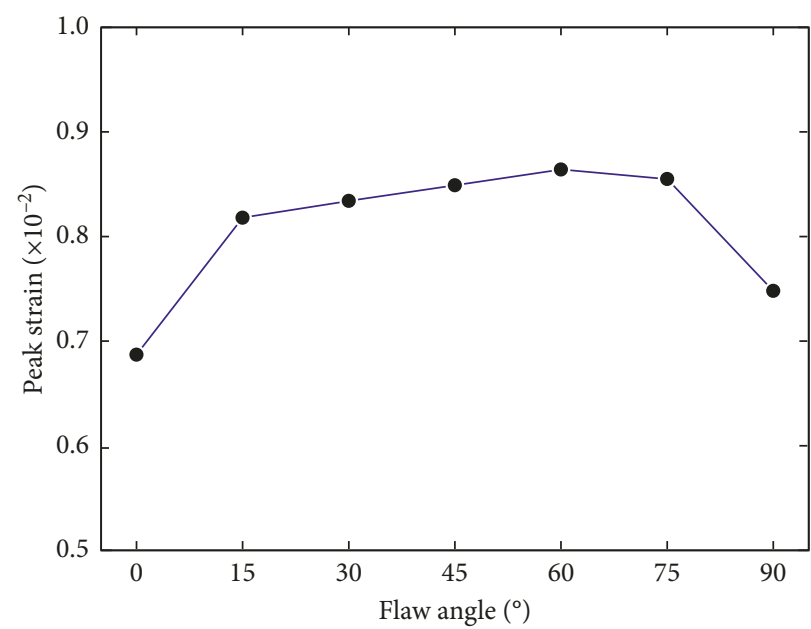

FIGURE 8: Influence of the flaw angle on peak strain of specimens with a constant ligament angle of $0^{\circ}$.

deformation properties of the defected sandstone specimens are plotted against the ligament angles in Figures 9-12. The dynamic stress-strain curves of sandstone specimens containing two elliptical flaws with various ligament angles are shown in Figure 9. The curve shapes are similar when the ligament angle reaches $30^{\circ}$, and the influence of the ligament angle on the curve shapes is less insignificant compared to that of the flaw angle. The relationship between the dynamic strength and the ligament angle is presented in Figure 10. The dynamic strength decreases first, then increases, and finally decreases nonlinearly with the ligament angle increasing, and the maximum value of $103.5 \mathrm{MPa}$ is obtained at a critical angle of $\beta=90^{\circ}$. When the ligament angle increases from $90^{\circ}$ to $150^{\circ}$, the dynamic strength decreases with a reduction from $18.50 \%$ to $21.26 \%$, which indicates that dynamic strength changes marginally as $\beta$ reaches $90^{\circ}$.

Figure 11 shows the effects of the ligament angle on the dynamic Young's modulus. The trend of Young's modulus is similar to that of the strength decreasing first, then 


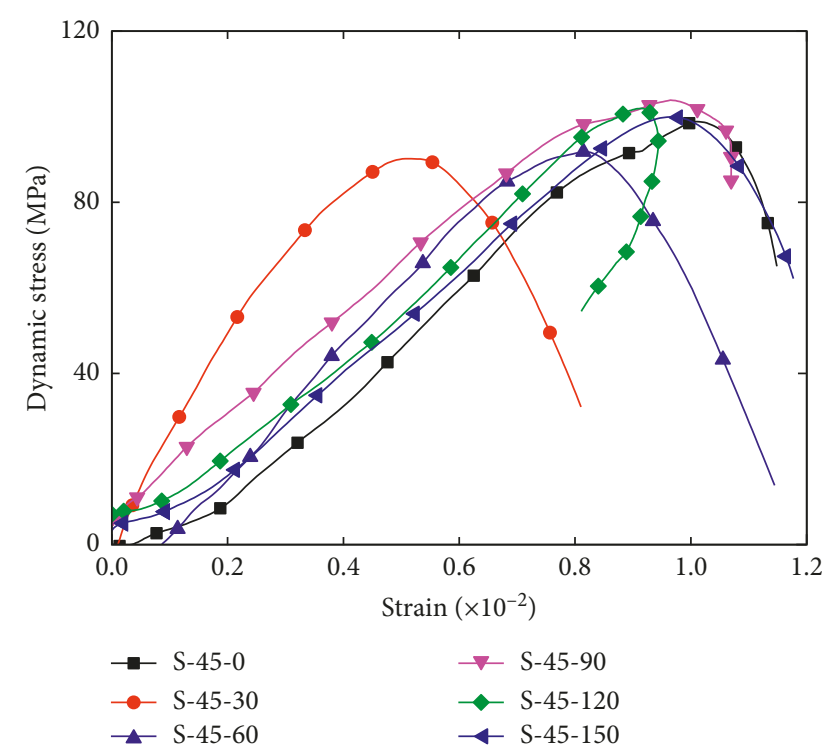

FIGURE 9: Influence of the ligament angle on the dynamic stressstrain curves of specimens with a constant flaw angle of $0^{\circ}$.

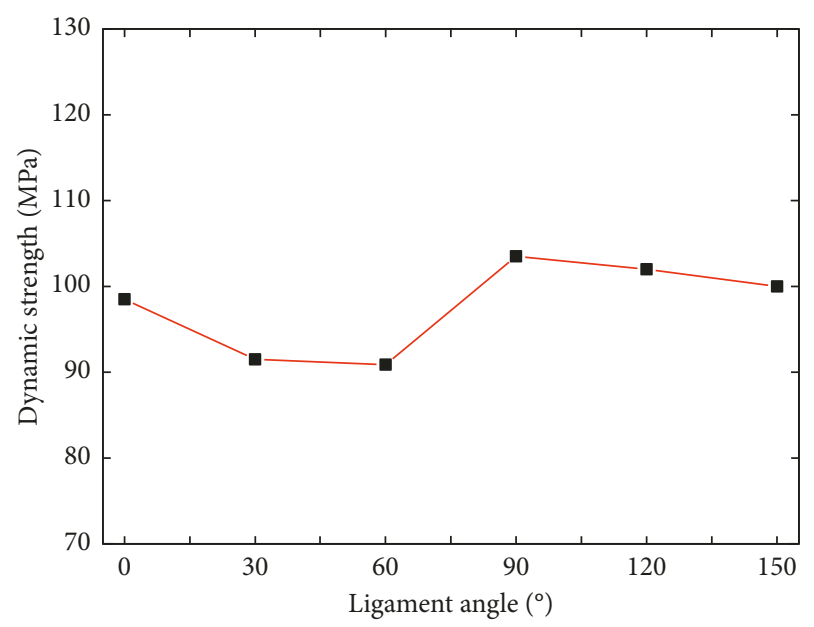

FIGURE 10: Influence of the ligament angle on the dynamic strength of specimens with a constant flaw angle of $0^{\circ}$.

increasing, and finally decreasing with a maximum of $12.66 \mathrm{GPa}$ at $\beta=90^{\circ}$. It can be seen from Figure 11, the dynamic Young's modulus changes marginally overall, indicating that the influence of the ligament angle on the dynamic Young's modulus is insignificant.

The relationship between the peak strain and the ligament angle is shown in Figure 12. The dynamic peak strain first decreases when $\alpha$ ranges from $0^{\circ}$ to $90^{\circ}$ (except $\alpha=60^{\circ}$ ), reaching the minimum value of $0.467 \%$ when $\alpha=90^{\circ}$ but then increases for $\alpha$ between $90^{\circ}$ and $150^{\circ}$.

From the above analysis, it can be concluded that the dynamic mechanical and deformation parameters are closely related to the flaw geometries. The results indicate that the effect of the flaw inclination angle on the dynamic strength and Young's modulus is more significant than that of the ligament angle but is less on the deformation.

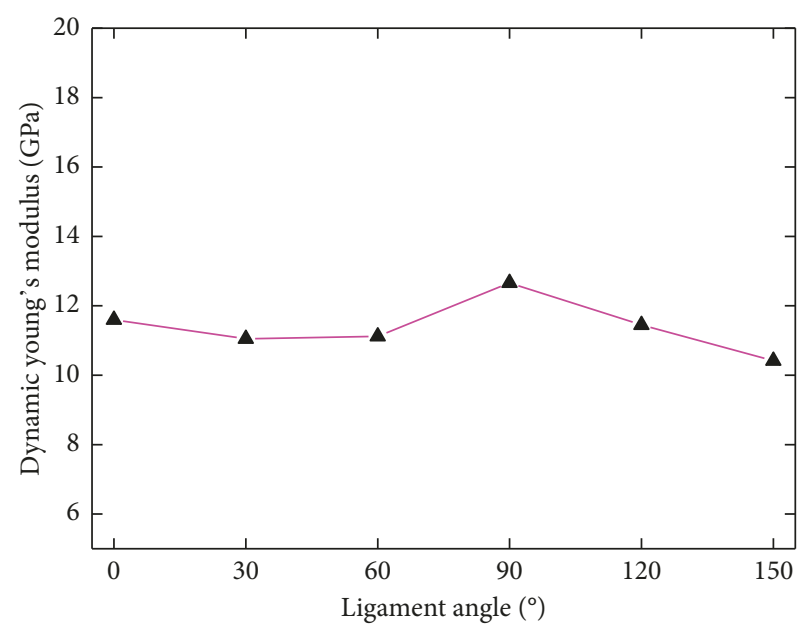

FIGURE 11: Influence of the ligament angle on the dynamic Young's modulus of specimens with a constant flaw angle of $0^{\circ}$.

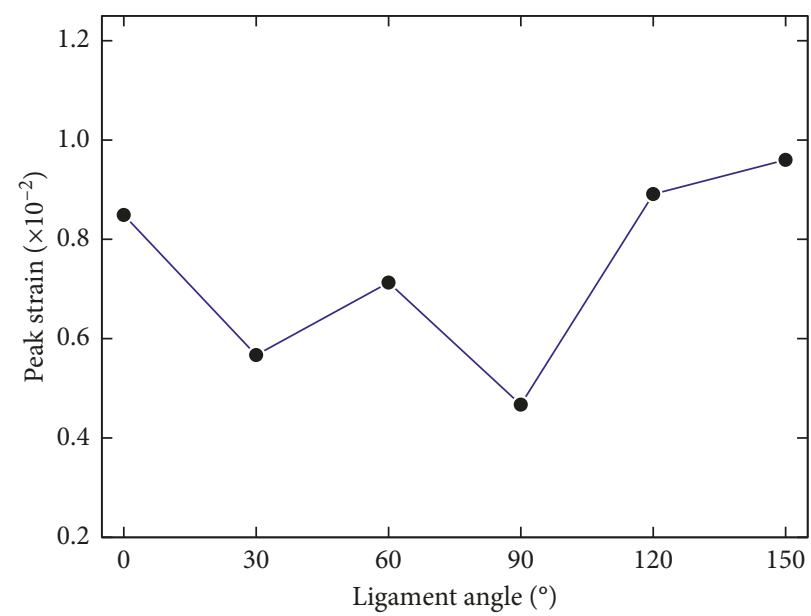

FIGURE 12: Influence of the ligament angle on the peak strain of specimens with a constant flaw angle of $0^{\circ}$.

\section{Crack Propagation and Failure Patterns}

4.1. Failure Patterns. The failure patterns of defected specimens are vital to interpret the entire cracking sequence and the failure mechanisms of rock under dynamic loading. Figures 13 and 14 present the final failure modes of sandstone specimens with double elliptical flaws under dynamic loading. Figure 13(a) shows the final failure mode of a typical intact specimen. It can be seen that shear and axial splitting cracks are both observed during the crack propagation process, leading to a typical mixed shear and splitting mode. Both flaw inclination angle and ligament angle affect the ultimate failure modes of the flawed specimens and make them more complicated.

Figure 13 depicts the influence of the flaw angle on the final failure modes of defected sandstone specimens with a consistent ligament angle of $0^{\circ}$. It can be seen from Figures 13(b)-13(h) that three types of failure modes are identified 


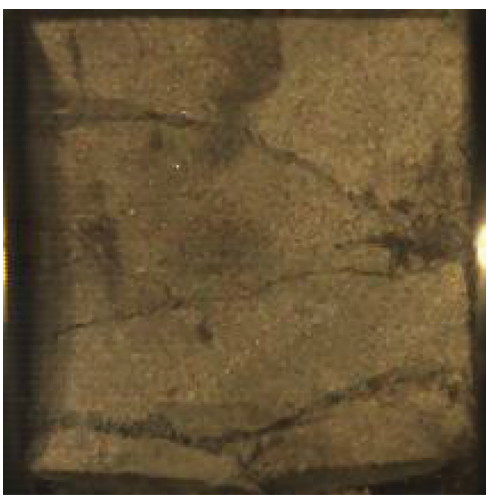

(a)

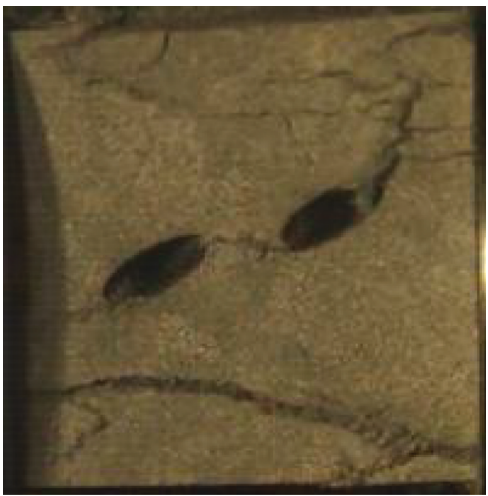

(d)

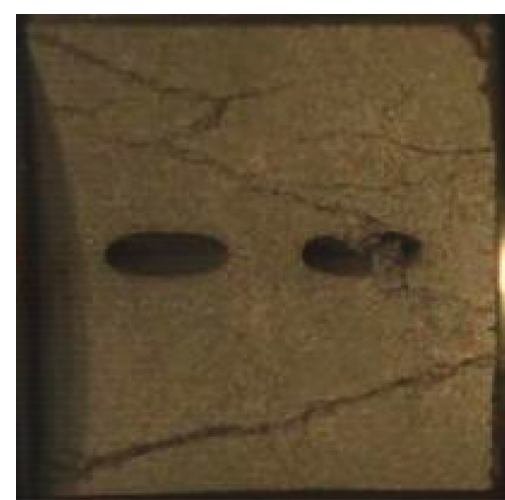

(b)

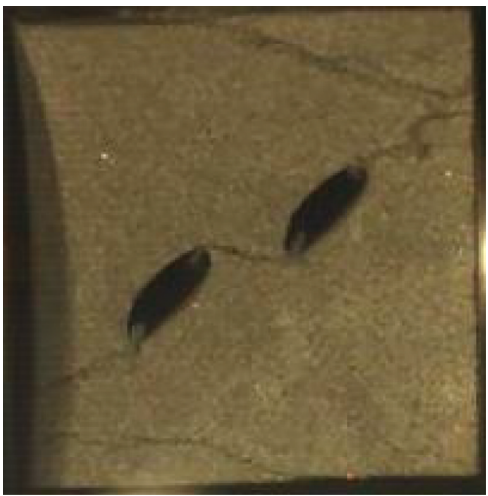

(e)

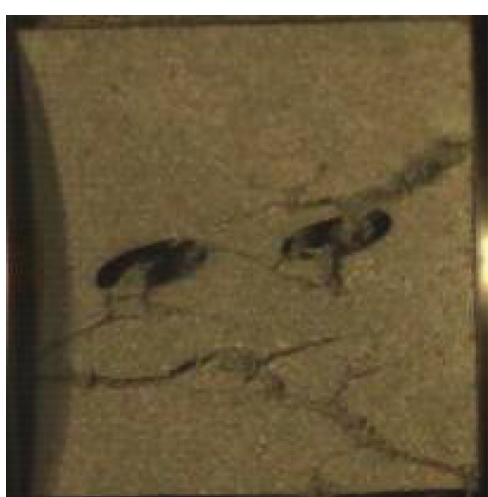

(c)

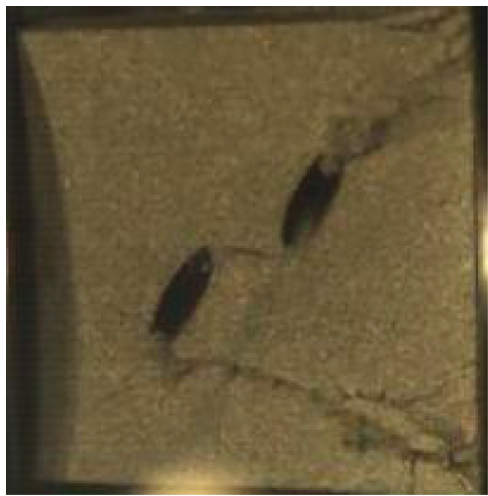

(f)

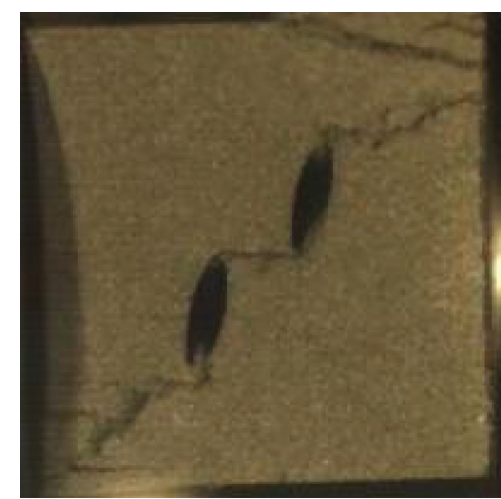

(g)

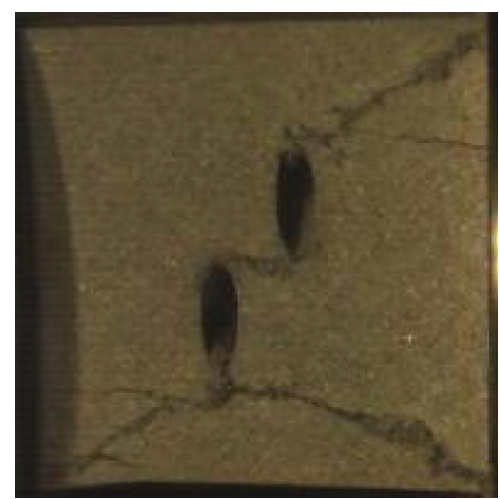

(h)

Figure 13: Effect of the flaw inclination angle on the final failure patterns of defected sandstone specimens under dynamic loading. (a) Intact. (b) S-0-0. (c) S-15-0. (d) S-30-0. (e) S-45-0. (f) S-60-0. (g) S-75-0. (h) S-90-0.

by analyzing the crack coalescence between the preexisting flaw tips under dynamic loading:

Type I: shear crack coalescence outside the flaw area, $\alpha=0^{\circ}$

Type II: shear crack coalescence inside the bridge area, $\alpha=15^{\circ}-60^{\circ}$

Type III: tensile crack coalescence inside the bridge area, $\alpha=75^{\circ}$ and $90^{\circ}$

It is concluded that crack coalescence type inside the ligament area changes from shear one to tensile one as the flaw inclination angle increasing.
Figure 14 shows the influence of the ligament angle on the final failure modes of defected sandstone specimens with a consistent flaw inclination angle of $45^{\circ}$. It can be seen from Figure 14 that the final failure modes are divided into three types by analyzing the crack coalescence under dynamic loading:

Type II: shear crack coalescence inside the bridge area, $\beta=0^{\circ}$ and $30^{\circ}$

Type IV: wing crack coalescence along the loading direction, $\beta=60^{\circ}-120^{\circ}$

Type V: crack coalescence in a curvilinear path within the bridge area, $\beta=150^{\circ}$ 


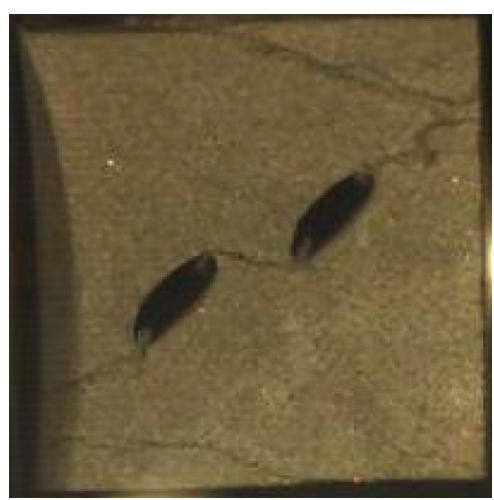

(a)

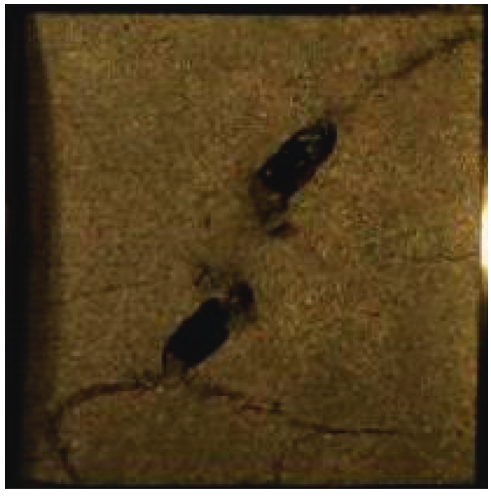

(d)

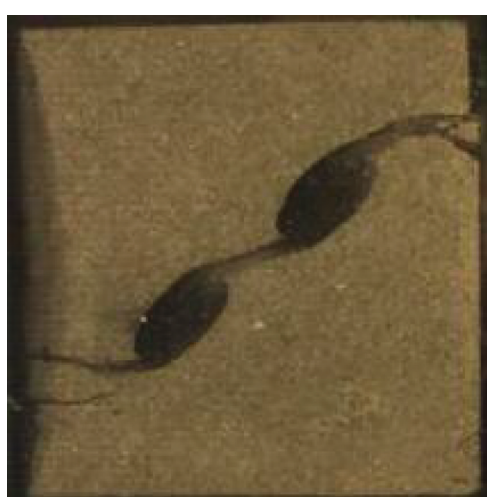

(b)

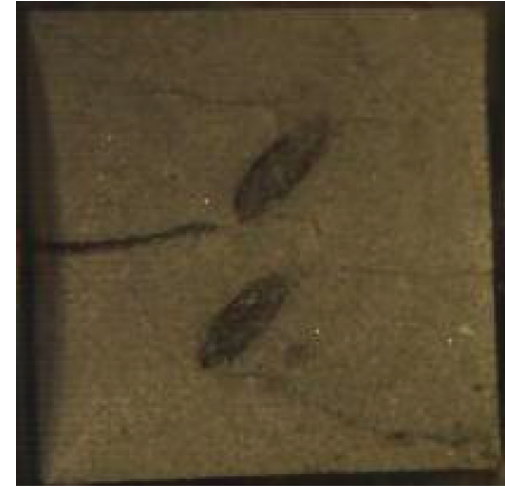

(e)

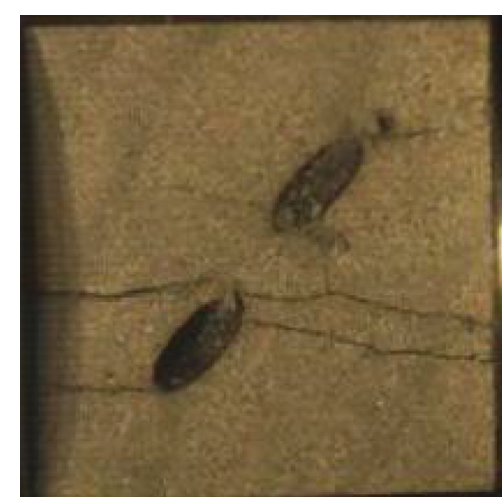

(c)

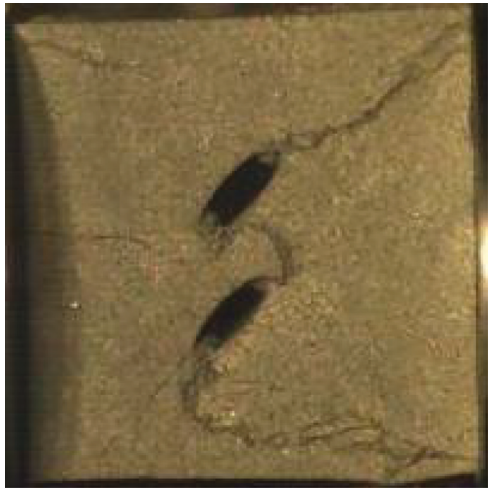

(f)

FIGURE 14: Effect of the ligament angle on the final failure patterns of defected sandstone specimens under dynamic loading. (a) S-45-0. (b) S-45-30. (c) S-45-60. (d) S-45-90. (e) S-45-120. (f) S-45-150.

It is found that there is no crack coalescence inside the bridge area and the dominated cracks are almost all around the preexisting flaws for $\beta$ within a certain range $\left(60^{\circ}-120^{\circ}\right)$. Totally, five typical types of failure modes are identified based on the crack coalescence.

4.2. Microscopic Analysis of Crack Coalescence. The surface morphology for fracturing usually reveals the failure process and energy evolution [46]. Scanning electron microscopy (SEM) has been used for many tests to analyze microscopic cracking characteristics, including triaxial compression tests [47, 48], rock after high-temperature treatment [25], and failure mechanism by supercritical $\mathrm{CO}_{2}$ jet impingement [49]. In this investigation, crack coalescence in the bridge area was examined by SEM. Figure 15 represents the petrographic image analysis for shear and tensile crack coalescence, respectively.

As shown in Figures 15(a) and 15(b), the overall shape of the shear fractography section performs a wavy terrain extending to farther positions. Smooth shear bands (Figure 15(b)), cleavage steps (Figure 15(b)), coarse scratches (Figure 15(a)), and pulverized rock powder (Figures 15(a) and 15(b)) are all obtained. The smooth bands are mainly associated with quartz [50], the cleavage steps are affected by grain size and the orientation of the cleavage plane, and the scratches and the pulverized rock powder are usually dominated by fast crack propagation [51]. Shear friction leaves typical features containing river lines, step cracks, and intercalated dislocation on the collapsed surface. From Figures 15(c) and 15(d), the tensile failure section has a relatively flat feature with a small amount of tiny crystal debris, showing obvious traces of tensile cracks. The weaker crystal particles will be broken to produce a transgranular failure with a lumpy surface. However, there will be an intergranular damage along the interface among the grains if the strength of crystal grains is stronger.

4.3. Crack Propagation Behavior. Figures 16-20 present the typical visible crack initiation, propagation, and coalescence processes under dynamic loading. The numbers shown in these figures represent the occurrence sequences of cracks recorded by the high-speed camera, and the superscript letters indicate that the cracks initiate almost simultaneously from different positions of the specimen.

4.3.1. Type I: Specimen S-0-0. Figure 16 shows a typical fracturing process for type I mode of the defected specimen with $\alpha=\beta=0^{\circ}$. Shear crack 1 initiates from the interface between the specimen and transmitted bar with the dynamic stress of $98.5 \mathrm{MPa}$ at the time of $80 \mu \mathrm{s}$. Then it widens, intensifies, and lengthens along the loading direction. When the dynamic stress reaches $119.0 \mathrm{MPa}$ at $t=133.3 \mu \mathrm{s}$, the dextral crack 2 from the edge of the specimen and incident 


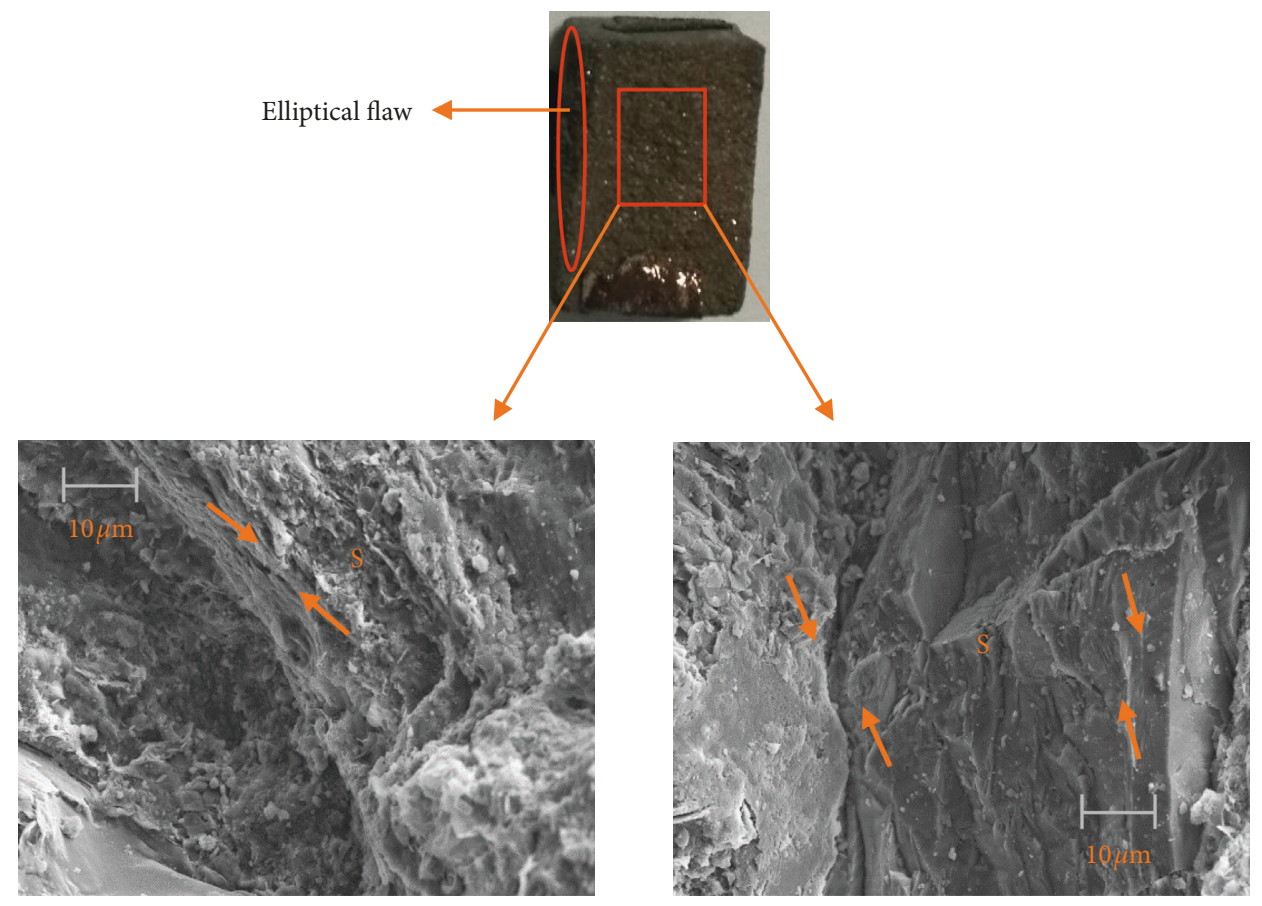

(a)

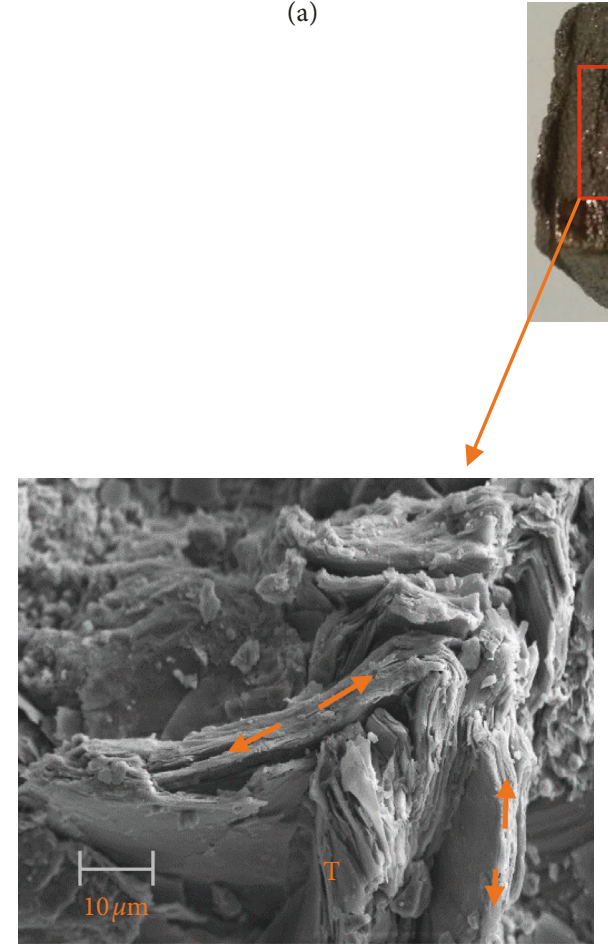

(c) (b)

Elliptical flaw

FiguRE 15: SEM images of typical crack coalescence between two flaws: (a, b) specimen S-45-0; (c, d) specimen S-90-0. The opposite arrows and the reverse arrows represent slipping and tensile area, respectively, and $\mathrm{S}$ and $\mathrm{T}$ represent shear and tensile cracks, respectively.

bar initiates and propagates to the flaw area. Meanwhile, pulverized rock powder is found in the internal walls of the oval flaw as the rockburst in rock engineering. The specimen does not collapse at the peak stress. When the stress drops to 97.2 $\mathrm{MPa}$ at $t=173.3 \mu \mathrm{s}$, far-field crack 3 generates in the middle of the crack 1 , and subsequently, shear crack 4 is found away from the flaw. As the dynamic stress unloading to $78.3 \mathrm{MPa}$, tensile cracks $5^{\mathrm{a}-\mathrm{b}}$ and shear crack $5^{\mathrm{c}}$ emerge from the edge and the right flaw of the specimen, respectively, causing the ultimate failure of the specimen. Obviously, there is no crack coalescence between the double preexisting flaws among the whole process. 

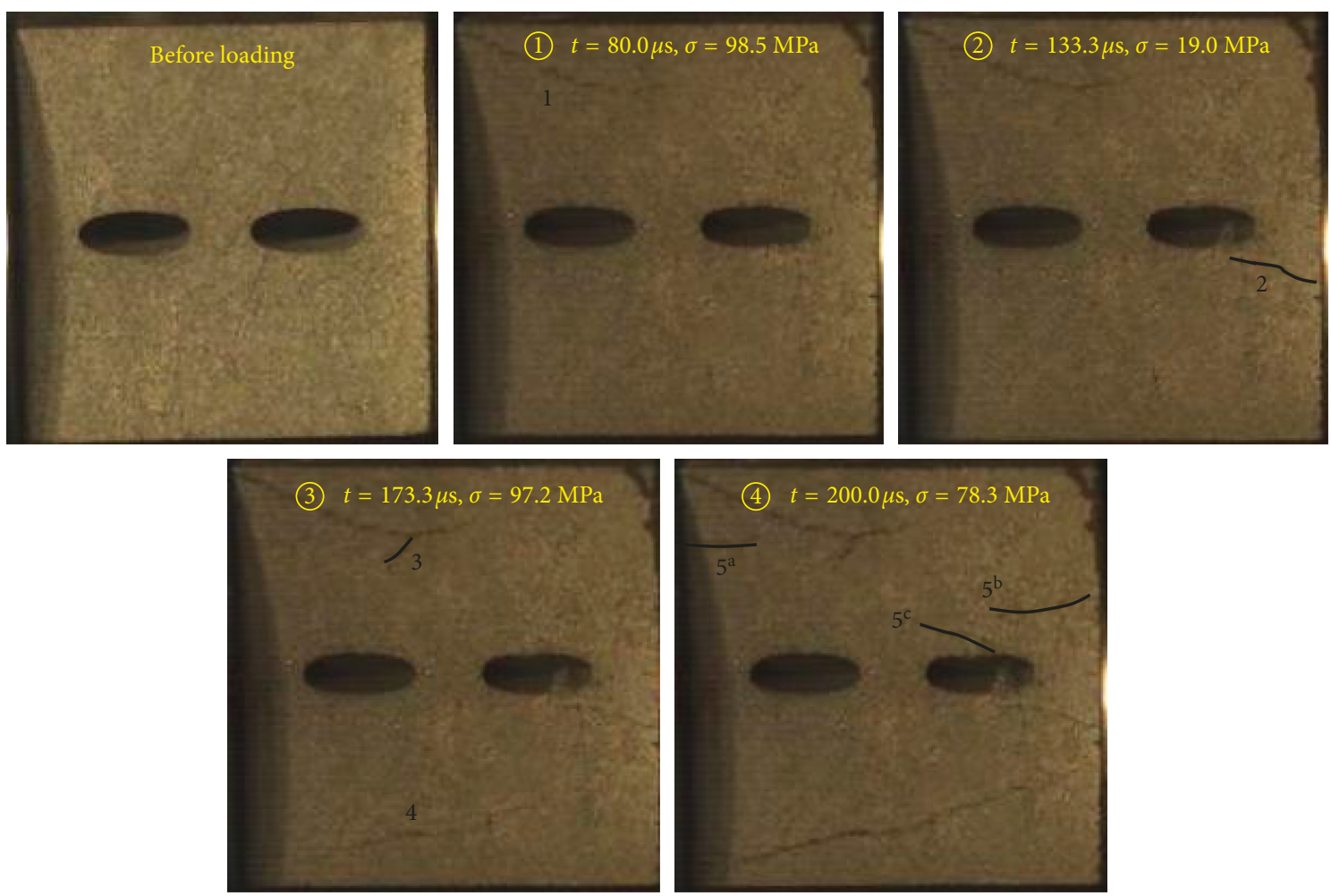

(a)

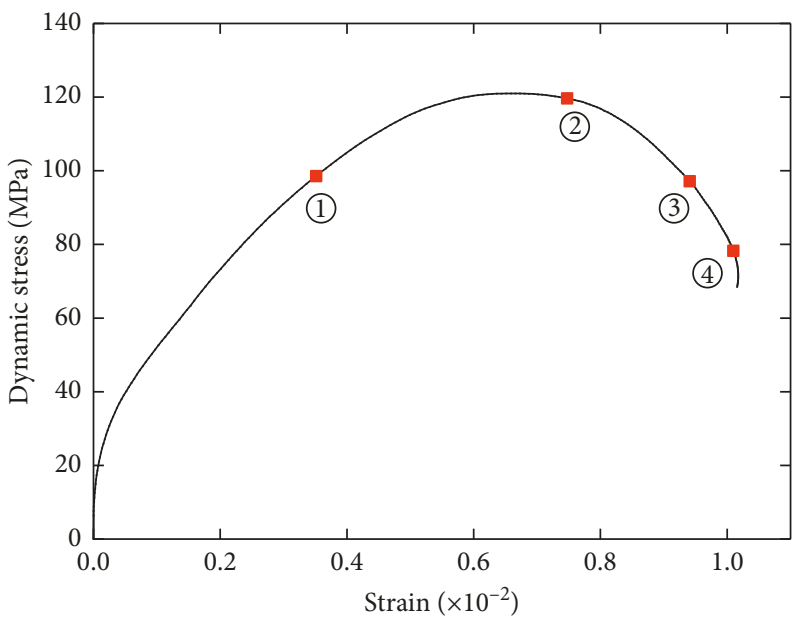

(b)

Figure 16: Fracturing process of type I mode with its corresponding dynamic stress-strain curve $\left(\alpha=\beta=0^{\circ}\right)$.

4.3.2. Type II: Taking Specimen S-45-0 as an Example. Figure 17 depicts a typical fracturing process for type II mode of the defected specimen with $\alpha=45^{\circ}$ and $\beta=0^{\circ}$. Shear crack $1^{\mathrm{a}}$ coalescence between the ligament area occurs before the peak stress, and shear crack $1^{\mathrm{b}}$ initiates from the flaw tips at the same time. As the dynamic stress increases to $96.2 \mathrm{MPa}$, another shear crack 2 generates at the outer tips of the other flaw and extends to the edge of the specimen. After the initiation of crack 2, the dynamic stress reaches the peak. However, no new obvious crack is observed at the peak strength except the longer and wider original ones than before. When the stress marginally drops to $93.5 \mathrm{MPa}$ at $t=200.0 \mu \mathrm{s}$, far-field crack 3 generates at the interface between the specimen and the incident bar and propagates to the upper edge of the specimen. When the stress drops to $67.6 \mathrm{MPa}$, lateral tensile cracks $4^{\mathrm{a}-\mathrm{b}}$ initiate at the edges. At this moment, original cracks $1^{\mathrm{b}}$ and 3 have a connection, resulting surface spalling with much pulverized rock powder.

4.3.3. Type III: Taking Specimen S-90-0 as an Example. Figure 18 summarizes a typical crack evolution for type III mode of the defected specimen with $\alpha=90^{\circ}$ and $\beta=0^{\circ}$. When the specimen is loaded to $51.4 \mathrm{MPa}$, tensile crack 1 generates at the inner tips of double flaws, and then crack coalescence occurs instantaneously with slight surface spalling in the 

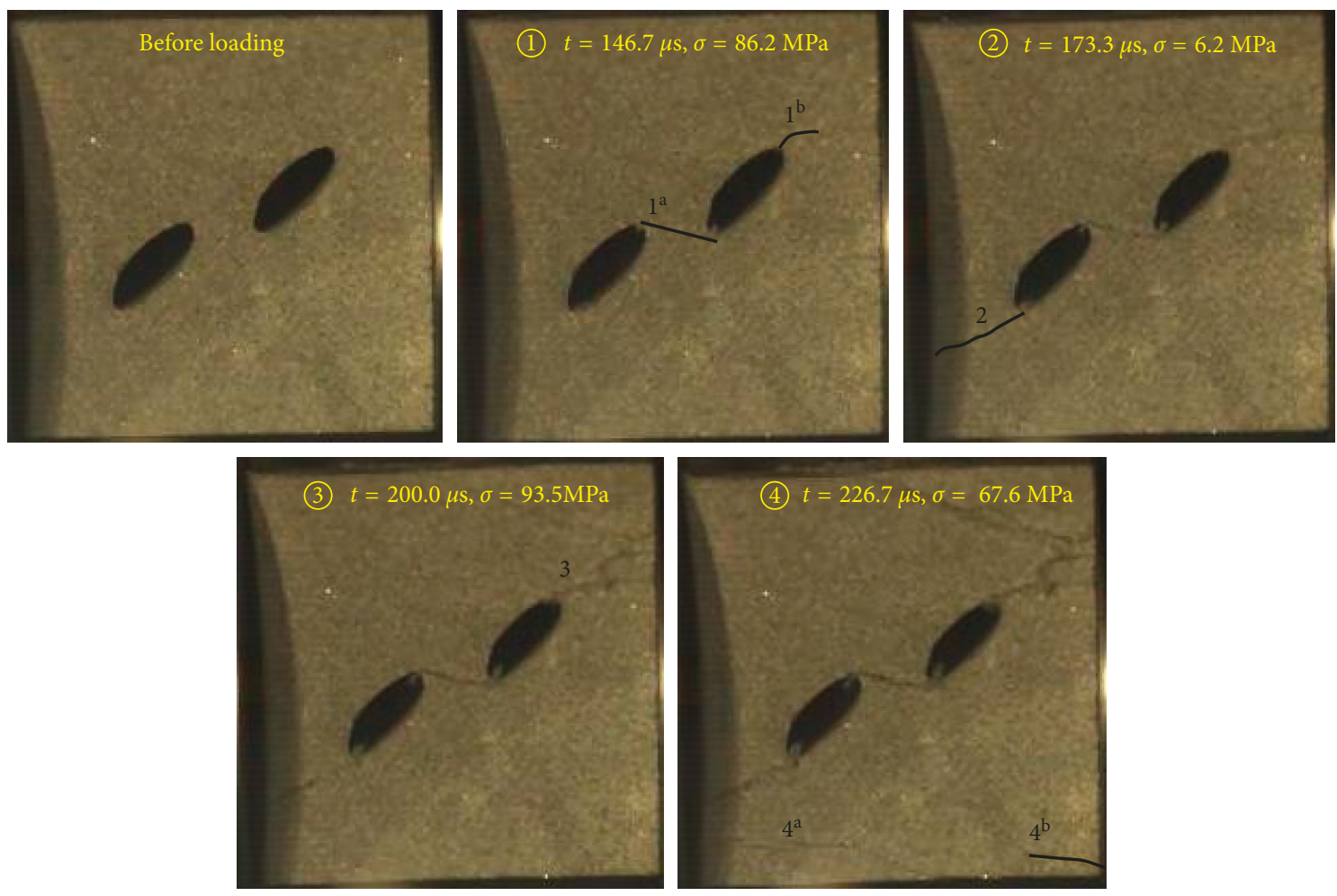

(a)

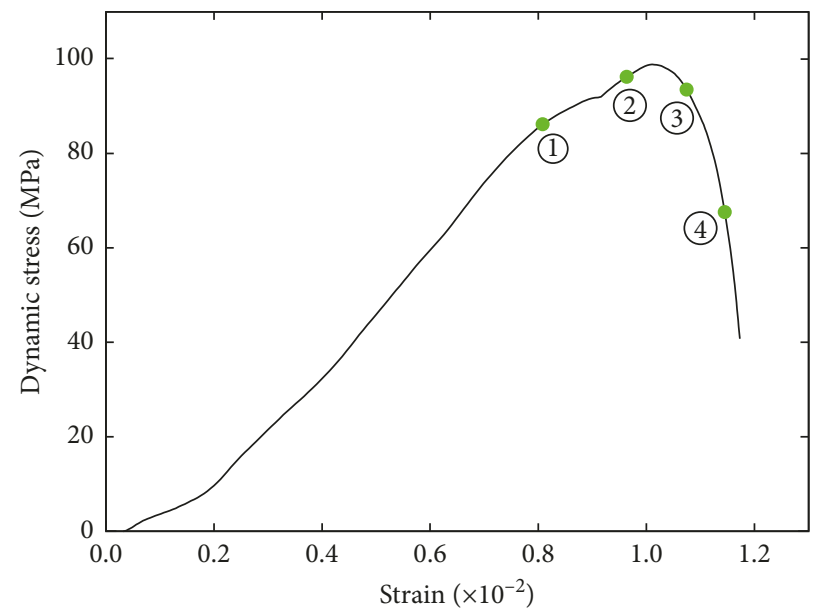

(b)

FIgURE 17: Fracturing process of type II mode with its corresponding dynamic stress-strain curve $\left(\alpha=45^{\circ}, \beta=0^{\circ}\right)$.

bridge area. With the dynamic stress increasing to $71.4 \mathrm{MPa}$, cracks $2^{\mathrm{a}-\mathrm{b}}$ initiate at the outer tip of the left flaw and propagate downward along diagonal directions, finally reaching the edge of the specimen. When the stress drops to $51.4 \mathrm{MPa}$ at $t=160.0 \mu \mathrm{s}$, crack 3 emerges from the outer tip of the right flaw and grows along the diagonal direction, ultimately making the specimen failure with original cracks together.

4.3.4. Type IV: Taking Specimen S-45-120 as an Example. The typical crack evolution for type IV mode of the defected specimen with $\alpha=45^{\circ}$ and $\beta=120^{\circ}$ is plotted in Figure 17. As can be seen from Figure 19, the cracking production is concentrated around the peak value and in the postpeak stage. The initial crack $1^{\mathrm{a}}$ emerges at the outer tip of the downward flaw when the dynamic stress reaches 101.6 MPa; meanwhile, spalling $1^{\mathrm{b}}$ is observed in the outer tip of the other flaw. Subsequently, the dynamic stress increases to the peak. Then, the stress slightly drops to $96.9 \mathrm{MPa}$, and a tensile crack 2 generates from the edge of the specimen and propagates stably. As the stress continues to unload to 85.4 MPa at $t=240.0 \mu \mathrm{s}$, a wing tensile crack 3 initiates at the outer tip of the upper flaw where original spalling grows. Then, the supporting structure of the specimen is damaged into a tensile-dominated failure, but the bridge area is still in good condition. 

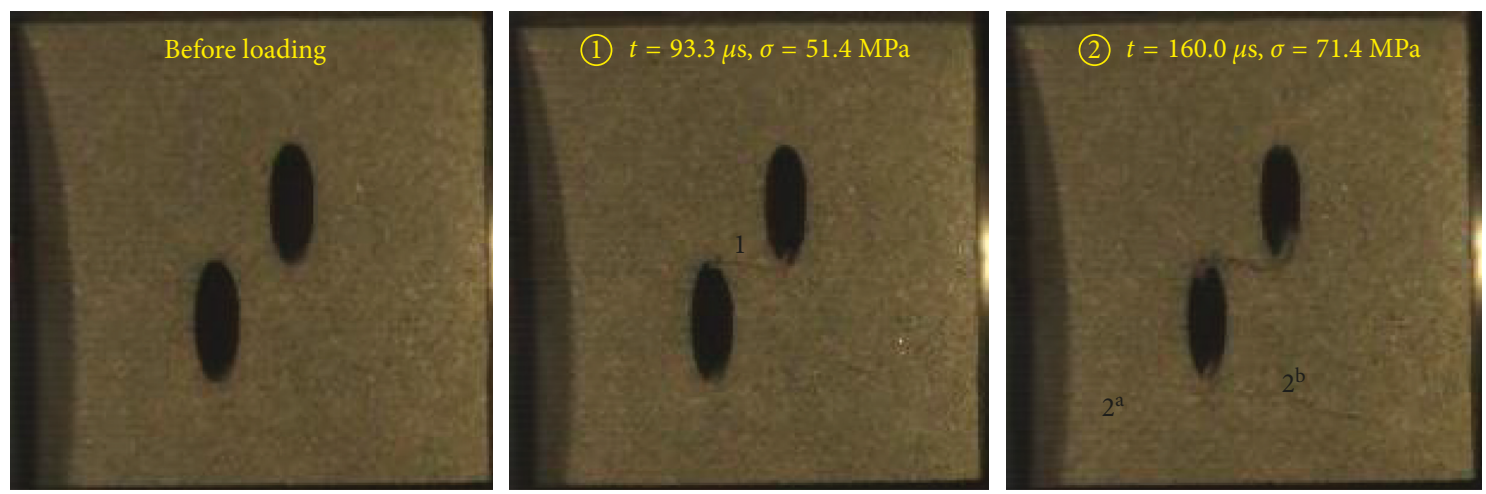

(3) $t=160.0 \mu \mathrm{s}, \sigma=51.4 \mathrm{MPa}$

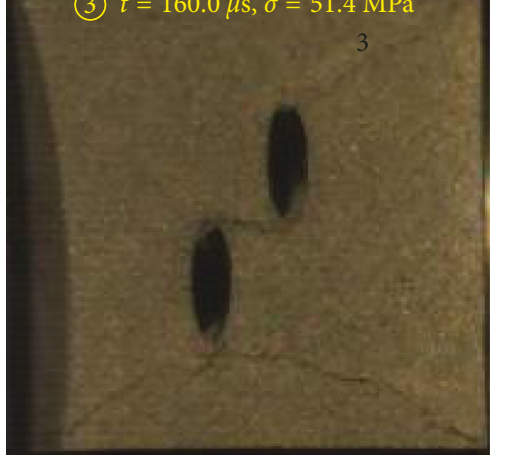

(a)

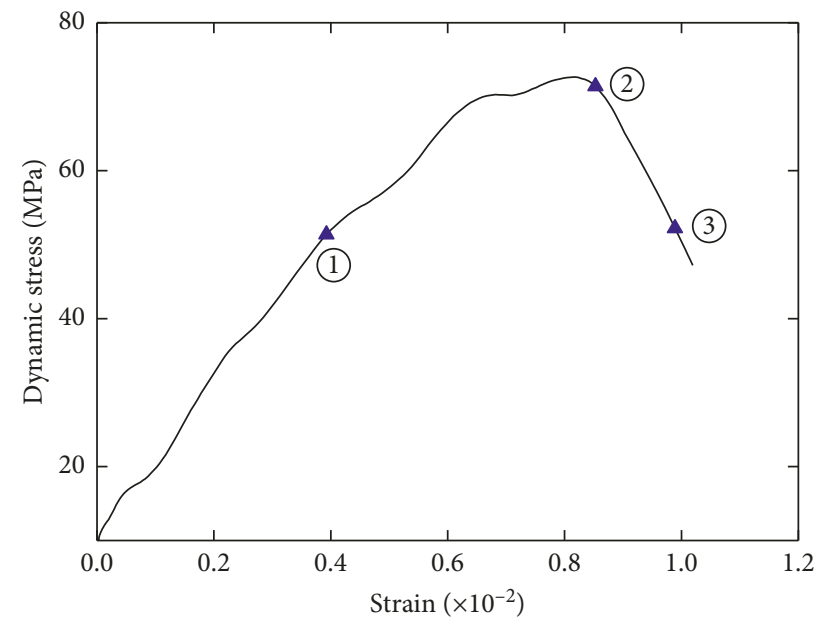

(b)

FIGURE 18: Fracturing process of type III mode with its corresponding dynamic stress-strain curve $\left(\alpha=90^{\circ}, \beta=0^{\circ}\right)$.

4.3.5. Type V: Specimen S-45-150. Figure 20 displays a typical crack evolution for type $\mathrm{V}$ mode of the defected specimen with $\alpha=45^{\circ}$ and $\beta=150^{\circ}$. It is obvious that the cracking production is concentrated around the peak value and in the postpeak stage. Shear crack 1 initiates at the inner tip of the downward flaw with the dynamic stress of 98.6 $\mathrm{MPa}$ at the time of $146.7 \mu \mathrm{s}$. Then, it propagates in a curvilinear path to coalesce with the inner tip of the other flaw. Subsequently, the dynamic stress reaches the peak value. Then, the stress drops with an increase in deformation. As the dynamic stress unloads to $93.2 \mathrm{MPa}$ at the postpeak stage, a shear crack 2 initiates at the tip in a diagonal direction of crack 1 tip but gradually propagates into a wing type with the stress continuing dropping. When the stress drops to $81.3 \mathrm{MPa}$, a pure shear crack 3 is observed at the outer tips of the upper flaw and extends to the edge of the specimen along the diagonal direction. Finally, the dynamic stress drops rapidly to point 4 , resulting in the generation of shear crack 4 at the interface between the transmitted bar and specimen with a little deformation. It is clear that both shear and tensile cracks are dominated during the failure process. 

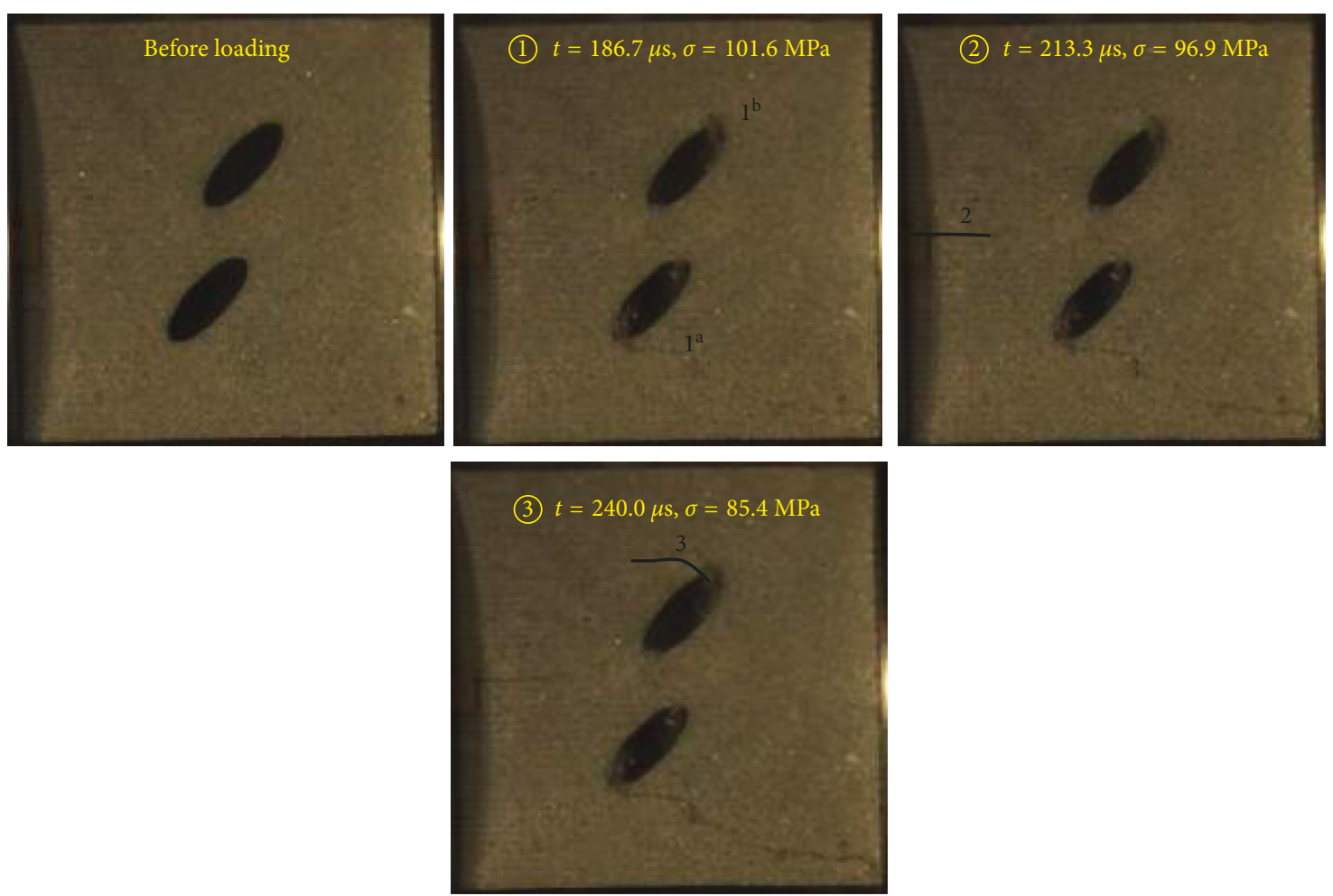

(a)

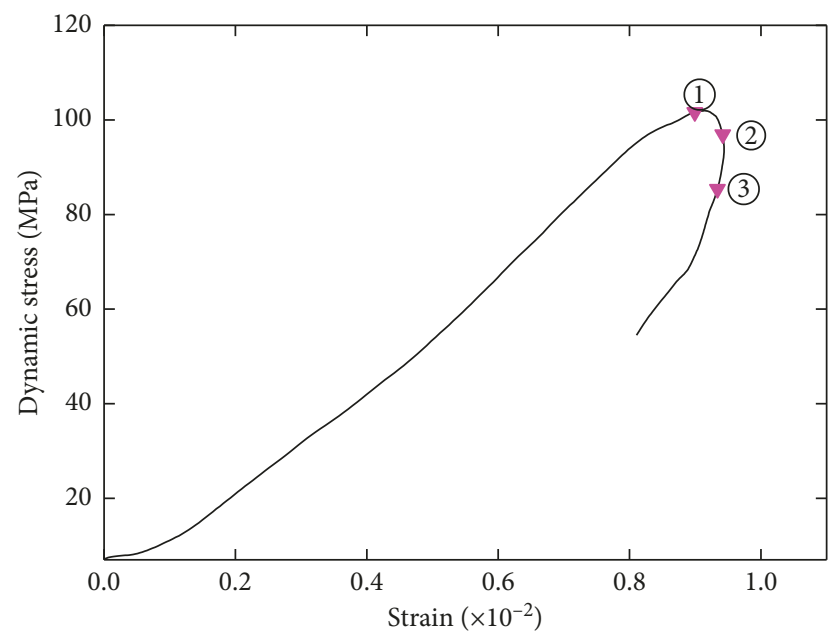

(b)

Figure 19: Fracturing process of type IV mode with its corresponding dynamic stress-strain curve $\left(\alpha=45^{\circ}, \beta=120^{\circ}\right)$.

\section{Conclusions}

(1) It is found that the dynamic strength and Young's modulus of green sandstone specimens with double elliptical flaws decrease with the flaw angle increasing, but these parameters are not obviously affected by the ligament angle. However, the influence of the ligament angle is more remarkable on the dynamic peak strain of sandstone specimens than that of the flaw angle. It indicates that the effect of the flaw angle on the dynamic strength and
Young's modulus is more significant than that of the ligament angle but is less on the deformation.

(2) The geometric parameters including flaw inclination angle and ligament angle of noncoplanar flaws have a significant influence on the final failure modes of the sandstone specimen. Five types of failure modes are identified based on the fracturing photos taken by a high-speed camera. Macroscale cracks mostly initiate at or near the flaw tips and propagate in different paths with varying flaw geometries, 

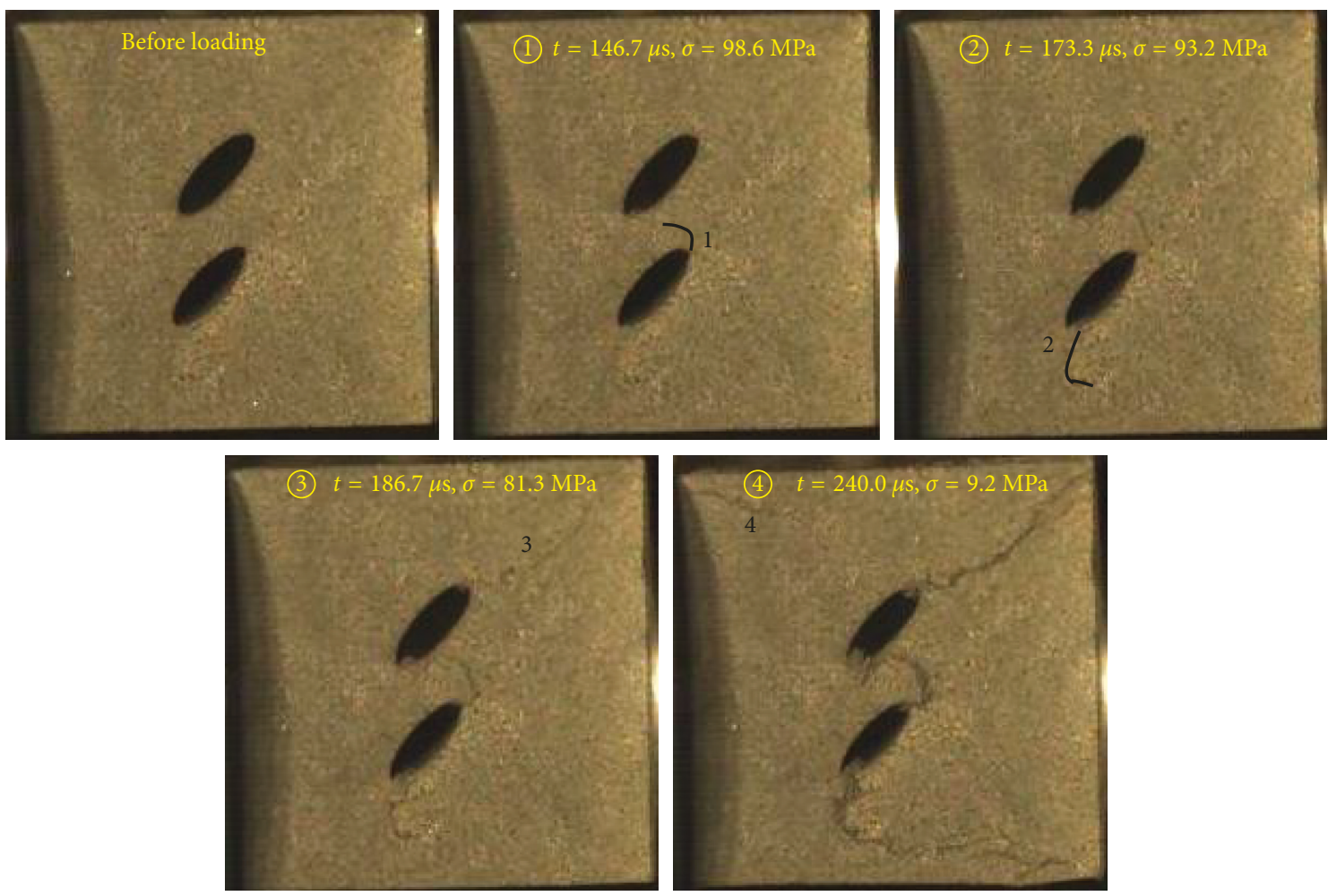

(a)

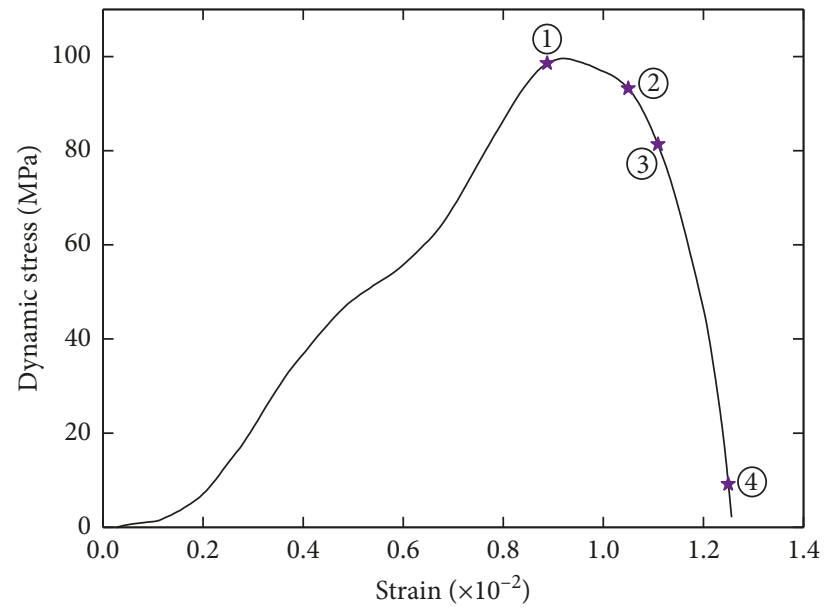

(b)

Figure 20: Fracturing process of type V mode with its corresponding dynamic stress-strain curve $\left(\alpha=45^{\circ}, \beta=150^{\circ}\right)$.

resulting in the ultimate failure including a mixture of shear cracks and tensile cracks.

(3) Surface morphology for fracturing was analyzed microscopically by SEM to demonstrate the occurrence of shear and tensile crack coalescence.

\section{Data Availability}

The data used to support the findings of this study are available from the corresponding author upon request.

\section{Conflicts of Interest}

The authors declare that they have no conflicts of interest.

\section{Acknowledgments}

The work was financially supported by the National Natural Science Foundation of China (51474250), the State Key Research Development Program of China (2016YFC0600706), the National Key Basic Research Program of China (2015CB060200), and the Fundamental Research Funds for the Central Universities of Central South University (Grant no. 2018zzts717).

\section{References}

[1] E. Hoek, "Practical rock engineering," Environmental and Engineering Geoscience, vol. 14, no. 1, pp. 55-57, 2008. 
[2] C. H. Park and A. Bobet, "Crack coalescence in specimens with open and closed flaws: a comparison," International Journal of Rock Mechanics and Mining Sciences, vol. 46, no. 5, pp. 819-829, 2009.

[3] S. P. Morgan, C. A. Johnson, and H. H. Einstein, "Cracking processes in Barre granite: fracture process zones and crack coalescence," International Journal of Fracture, vol. 180, no. 2, pp. 177-204, 2013.

[4] Z. J. Wen, X. Wang, Y. L. Tan, H. L. Zhang, W. P. Huang, and Q. H. Li, "A study of rockburst hazard evaluation method in coal mine," Shock and Vibration, vol. 2016, Article ID 8740868, 9 pages, 2016.

[5] L. N. Y. Wong and H. H. Einstein, "Fracturing behavior of prismatic specimens containing single flaws," in Proceedings of 41st U.S. Rock Mechanics Symposium-ARMA's Golden Rocks 2006-50 Years of Rock Mechanics, Golden, CO, USA, June 2006.

[6] L. N. Y. Wong and H. H. Einstein, "Systematic evaluation of cracking behavior in specimens containing single flaws under uniaxial compression," International Journal of Rock Mechanics and Mining Sciences, vol. 46, no. 2, pp. 239-249, 2009.

[7] L. N. Y. Wong and H. H. Einstein, "Using high speed video imaging in the study of cracking processes in rock," Geotechnical Testing Journal, vol. 32, no. 2, pp. 164-180, 2009.

[8] S. Q. Yang and H. W. Jing, "Strength failure and crack coalescence behavior of brittle sandstone samples containing a single fissure under uniaxial compression," International Journal of Fracture, vol. 168, no. 2, pp. 227-250, 2011.

[9] X. P. Zhang and L. N. Y. Wong, "Cracking processes in rocklike material containing a single flaw under uniaxial compression: a numerical study based on parallel bonded-particle model approach," Rock Mechanics and Rock Engineering, vol. 45, no. 5, pp. 711-737, 2012.

[10] C. J. Zou, L. N. Y. Wong, J. L. Jin, and B. S. Gan, “Different mechanical and cracking behaviors of single-flawed brittle gypsum specimens under dynamic and quasi-static loadings," Engineering Geology, vol. 201, no. 4, pp. 71-84, 2016.

[11] C. Zhao, H. Matsuda, C. Morita, and M. R. Shen, "Study on failure characteristic of rock-like materials with an open-hole under uniaxial compression," Strain, vol. 47, no. 5, pp. 405413, 2011.

[12] Q. B. Zhang and J. Zhao, "Determination of mechanical properties and full-field strain measurements of rock material under dynamic loads," International Journal of Rock Mechanics and Mining Sciences, vol. 60, no. 8, pp. 423-439, 2013.

[13] D. Y. Li, Q. Q. Zhu, Z. L. Zhou, X. B. Li, and P. G. Ranjith, "Fracture analysis of marble specimens with a hole under uniaxial compression by digital image correlation," Engineering Fracture Mechanics, vol. 183, no. 9, pp. 109-124, 2017.

[14] R. H. C. Wong, P. Lin, and C. A. Tang, "Experimental and numerical study on splitting failure of brittle solids containing single pore under uniaxial compression," Mechanics of Materials, vol. 38, no. 1-2, pp. 142-159, 2006.

[15] A. Bobet and H. H. Einstein, "Fracture coalescence in rocktype materials under uniaxial and biaxial compression," International Journal of Rock Mechanics and Mining Sciences, vol. 35, no. 7, pp. 863-888, 1998.

[16] R. H. C. Wong and K. T. Chau, "Crack coalescence in a rocklike material containing two cracks," International Journal of Rock Mechanics and Mining Sciences, vol. 35, no. 2, pp. 147-164, 1998.

[17] M. Sagong and A. Bobet, "Coalescence of multiple flaws in a rock-model material in uniaxial compression," International
Journal of Rock Mechanics and Mining Sciences, vol. 39, no. 2, pp. 229-241, 2002.

[18] S. Q. Yang, Y. H. Dai, L. J. Han, and Z. Q. Jin, "Experimental study on mechanical behavior of brittle marble samples containing different flaws under uniaxial compression," Engineering Fracture Mechanics, vol. 76, no. 12, pp. 1833-1845, 2009.

[19] S. Q. Yang, D. S. Yang, H. W. Jing, Y. H. Li, and S. Y. Wang, "An experimental study of the fracture coalescence behaviour of brittle sandstone specimens containing three fissures," Rock Mechanics and Rock Engineering, vol. 45, no. 4, pp. 563-582, 2012.

[20] C. H. Park and A. Bobet, "Crack initiation, propagation and coalescence from frictional flaws in uniaxial compression," Engineering Fracture Mechanics, vol. 77, no. 14, pp. 27272748, 2010.

[21] I. Gratchev, H. K. Dong, and K. Y. Chong, "Strength of rocklike specimens with pre-existing cracks of different length and width," Rock Mechanics and Rock Engineering, vol. 49, no. 11, pp. 4491-4496, 2016.

[22] X. T. Feng and W. Ding, "Experimental study of limestone micro-fracturing under a coupled stress, fluid flow and changing chemical environment," International Journal of Rock Mechanics and Mining Sciences, vol. 44, no. 3, pp. 437-448, 2007.

[23] S. Q. Yang, "Experimental study on deformation, peak strength and crack damage behavior of hollow sandstone under conventional triaxial compression," Engineering Geology, vol. 213, pp. 11-24, 2016.

[24] Y. H. Li, J. Y. Peng, F. P. Zhang, and Z. G. Qiu, "Cracking behavior and mechanism of sandstone containing a pre-cut hole under combined static and dynamic loading," Engineering Geology, vol. 213, pp. 64-73, 2016.

[25] Y. H. Huang, S. Q. Yang, W. L. Tian, J. Zhao, D. Ma, and C. S. Zhang, "Physical and mechanical behavior of granite containing pre-existing holes after high temperature treatment," Archives of Civil and Mechanical Engineering, vol. 17, no. 4, pp. 912-925, 2017.

[26] Y. Liu, F. Dai, L. Dong, N. Xu, and P. Feng, "Experimental investigation on the fatigue mechanical properties of intermittently jointed rock models under cyclic uniaxial compression with different loading parameters," Rock Mechanics and Rock Engineering, vol. 51, no. 1, pp. 47-68, 2018.

[27] T. Zhou and J. B. Zhu, "An experimental investigation of tensile fracturing behavior of natural and artificial rocks in static and dynamic brazilian disc tests," Procedia Engineering, vol. 191, pp. 992-998, 2017.

[28] E. Z. Lajtai and V. N. Lajtai, “The collapse of cavities," International Journal of Rock Mechanics and Mining Sciences and Geomechanics Abstracts, vol. 12, no. 4, pp. 81-86, 1975.

[29] P. Lin, R. H. C. Wong, and C. A. Tang, "Experimental study of coalescence mechanisms and failure under uniaxial compression of granite containing multiple holes," International Journal of Rock Mechanics and Mining Sciences, vol. 77, no. 4-6, pp. 313-327, 2015.

[30] C. G. Sammis and M. F. Ashby, "The failure of brittle porous solids under compressive stress states," Acta Metallurgica, vol. 34, no. 3, pp. 511-526, 1986.

[31] Y. H. Huang, S. Q. Yang, P. G. Ranjith, and J. Zhao, "Strength failure behavior and crack evolution mechanism of granite containing pre-existing non-coplanar holes: experimental study and particle flow modeling," Computers and Geotechnics, vol. 88, pp. 182-198, 2017. 
[32] S. Q. Yang, Y. H. Huang, W. L. Tian, and J. B. Zhu, "An experimental investigation on strength, deformation and crack evolution behavior of sandstone containing two oval flaws under uniaxial compression," Engineering Geology, vol. 217, pp. 35-48, 2017.

[33] H. Q. Li and L. N. Y. Wong, "Influence of flaw inclination angle and loading condition on crack initiation and propagation," International Journal of Solids and Structures, vol. 49, no. 18, pp. 2482-2499, 2012.

[34] X. B. Li, T. Zhou, and D. Y. Li, "Dynamic strength and fracturing behavior of single-flawed prismatic marble specimens under impact loading with a split-hopkinson pressure bar," Rock Mechanics and Rock Engineering, vol. 50, no. 1, pp. 29-44, 2017.

[35] D. Y. Li, T. J. Cheng, T. Zhou, and X. B. Li, "Experimental study of the dynamic strength and fracturing characteristics of marble specimens with a single hole under impact loading," Chinese Journal of Rock Mechanics Engineering, vol. 34, no. 2, pp. 249-260, 2015, in Chinese.

[36] C. Jiang, G. F. Zhao, J. Zhu, Y. X. Zhao, and L. Shen, "Investigation of dynamic crack coalescence using a gypsum-like 3D printing material," Rock Mechanics and Rock Engineering, vol. 49, no. 10, pp. 3983-3998, 2016.

[37] D. Y. Li, Z. Y. Han, X. L. Sun, and X. B. Li, "Characteristics of dynamic failure of marble with artificial flaws under split Hopkinson pressure bar tests," Chinese Journal of Rock Mechanics Engineering, vol. 36, no. 12, pp. 2872-2883, 2017, in Chinese.

[38] S. Q. Yang, H. W. Jing, and X. Tao, "Mechanical behavior and failure analysis of brittle sandstone specimens containing combined flaws under uniaxial compression," Journal of Central South University, vol. 21, no. 5, pp. 2059-2073, 2014.

[39] M. Chen, H. Jing, X. Ma, H. Su, M. Du, and T. Zhu, "Fracture evolution characteristics of sandstone containing double fissures and a single circular hole under uniaxial compression," International Journal of Mining Science and Technology, vol. 27, no. 3, pp. 499-505, 2017.

[40] Y. X. Zhou, K. Xia, X. B. Li et al., "Suggested methods for determining the dynamic strength parameters and mode-I fracture toughness of rock materials," International Journal of Rock Mechanics and Mining Sciences, vol. 49, no. 1, pp. 105-112, 2012.

[41] X. B. Li, T. Zhou, D. Y. Li, and Z. Y. Wang, "Experimental and numerical investigations on feasibility and validity of prismatic rock specimen in SHPB," Shock and Vibration, vol. 2016, Article ID 7198980, 13 pages, 2016.

[42] X. B. Li, T. S. Lok, and J. Zhao, "Dynamic characteristics of granite subjected to intermediate loading rate," Rock Mechanics and Rock Engineering, vol. 38, no. 1, pp. 21-39, 2005.

[43] X. B. Li, Z. L. Zhou, L. Hong, and T. B. Yin, "Large diameter SHPB tests with a special shaped striker," Journal of ISRM News, vol. 12, pp. 76-79, 2009.

[44] X. B. Li, Rock Dynamics: Fundamentals and Applications, Science Press, Beijing, China, 2014.

[45] J. M. Lifshitz and H. Leber, "Data processing in the split hopkinson pressure bar tests," International Journal of Impact Engineering, vol. 15, no. 6, pp. 723-733, 1994.

[46] E. Sharon, S. P. Gross, and J. Fineberg, "Energy dissipation in dynamic fracture," Physical Review Letters, vol. 76, no. 12, pp. 2117-2120, 1996.

[47] S. C. Hu, Y. L. Tan, H. Zhou et al., "Impact of bedding planes on mechanical properties of sandstone," Rock Mechanics and Rock Engineering, vol. 50, no. 8, pp. 2243-2251, 2017.
[48] D. Li, Z. Sun, T. Xie, and X. Li, "Energy evolution characteristics of hard rock during triaxial failure with different loading and unloading paths," Engineering Geology, vol. 228, pp. 270-281, 2017.

[49] Z. He, G. Li, S. Tian, H. Wang, Z. Shen, and J. Li, "SEM analysis on rock failure mechanism by supercritical $\mathrm{CO}_{2}$ jet impingement," Journal of Petroleum Science and Engineering, vol. 146, no. 10, pp. 111-120, 2016.

[50] M. G. Norton and B. K. Atkinson, "Stress-dependent morphological features on fracture surfaces of quartz and glass," Tectonophysics, vol. 77, no. 3-4, pp. 283-295, 1981.

[51] Q. B. Zhang and J. Zhao, "Quasi-static and dynamic fracture behaviour of rock materials: phenomena and mechanisms," International Journal of Fracture, vol. 189, no. 1, pp. 1-32, 2014. 


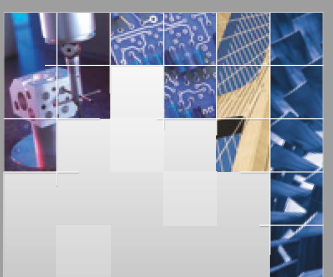

\section{Enfincering}
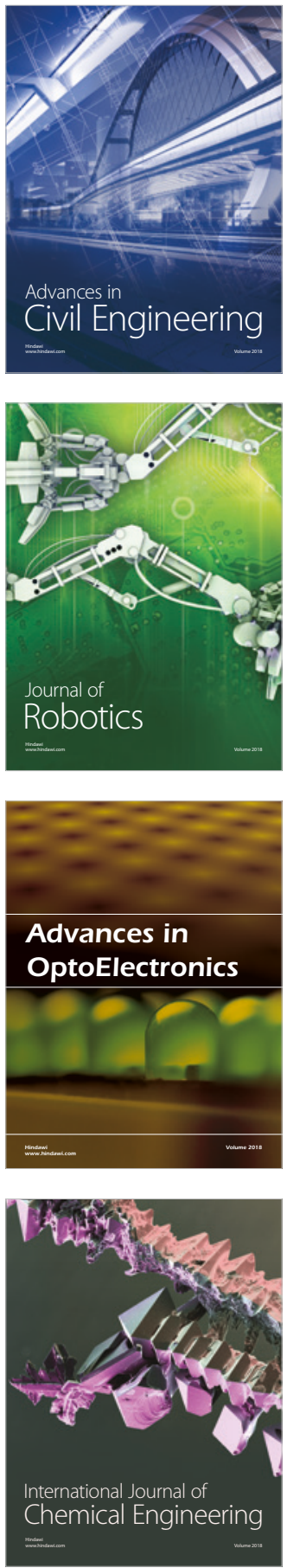

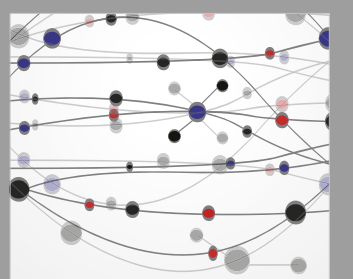

\section{Rotating \\ Machinery}

The Scientific World Journal

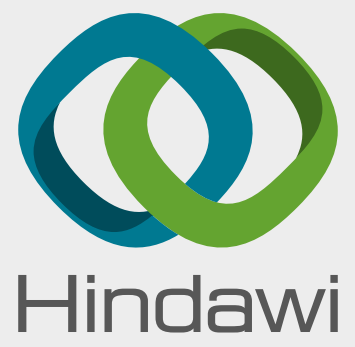

Submit your manuscripts at

www.hindawi.com
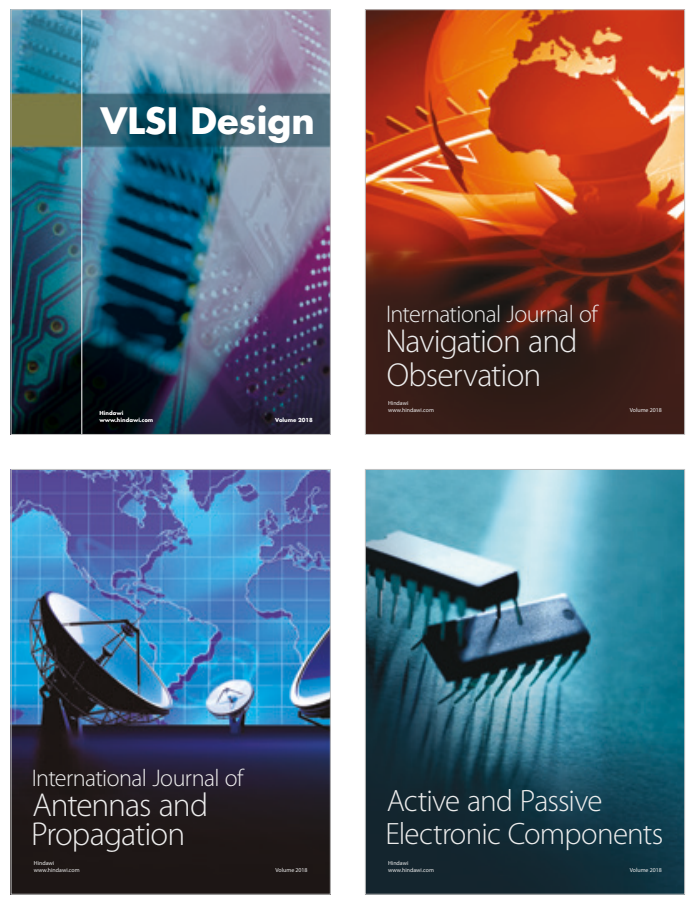
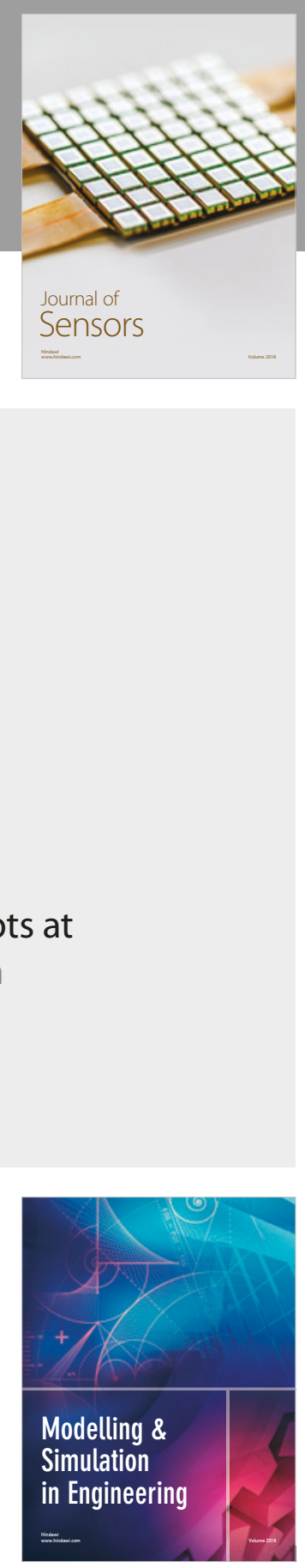

\section{Advances \\ Multimedia}
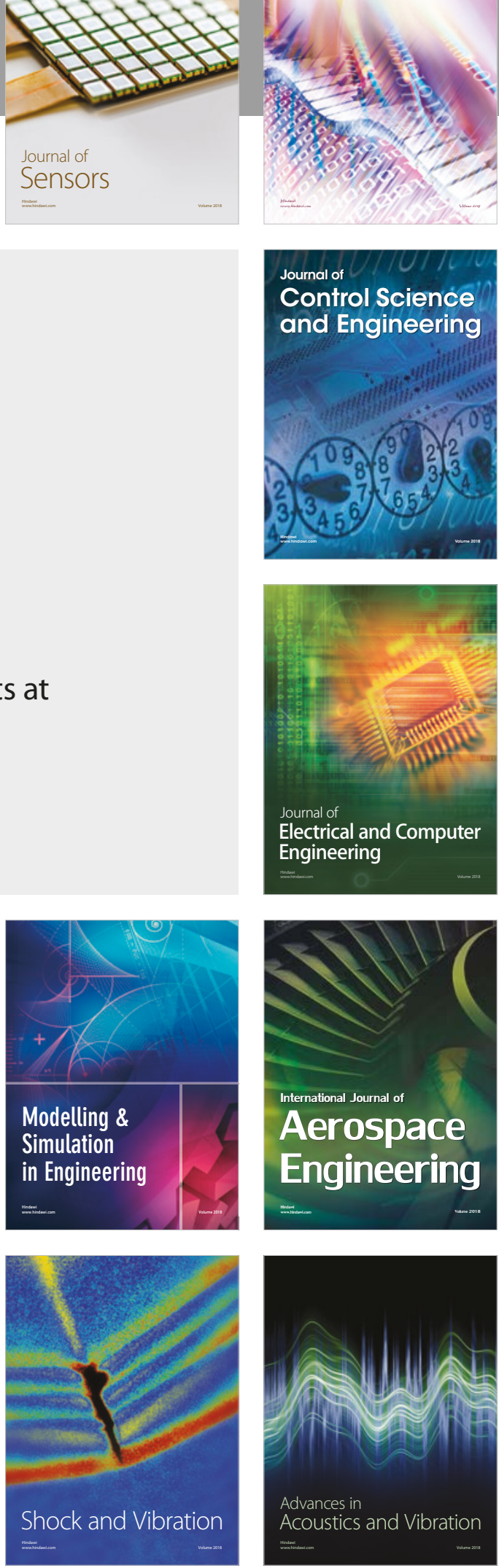